\title{
Algunos aspectos jurídico-constitucionales con relación al abordaje de buque pirata en alta mar: función de policía de la armada, abordaje y registro de la nave y pautas en orden a la de- tención de sospechosos
}

\author{
Alberto Oehling de los Reyes \\ Doctor en Derecho. Profesor de Derecho Constitucional \\ Universidad de las Islas Baleares
}

Recibido: 20.05.2011

Aceptado: 31.05 .2011

\begin{abstract}
Resumen: El fortalecimiento de vías legales para asegurar el respeto de los derechos humanos de los prisioneros o detenidos por parte de los miembros de las Fuerzas Armadas en operaciones en el exterior es una cuestión de indudable relevancia constitucional. Ese interés ha tomado más importancia en España a raíz de la cada vez mayor implicación y peligrosidad de las misiones que desarrolla el Ejército en el extranjero, como por ejemplo, Irak, Afganistán o la Operación Atalanta. El presente trabajo tiene por objeto hacer un análisis aproximativo de en qué medida puede actuar la Armada española, en orden a la detención de piratas en alta mar, tratando de preservar los derechos humanos de los detenidos y, más allá, en pro de la garantía, en la medida de lo posible, de los derechos fundamentales contenidos en la Constitución de 1978.
\end{abstract}

Palabras clave: Armada española, Constitución española, derechos humanos, derechos fundamentales, dignidad de la persona.

Abstract: The strengthening of legal ways to guarantee the human right's respect of the prisoners or the persons under arrest made by the members of the Army in foreign operations is a cuestion of undoubted constitutional importance. That interest has had more significance in Spain with the growing implication and riskiness of the soldier' missions abroad; for example: Irak, Afganistán o la Operación Atalanta. This work has the objective of doing an approximate analysis of how the Spanish Navy, can arrest pirates trying to preserve the human rights of the arrested persons and, further away, in favour of the guarantee, if possible, of the fundamental rights content in the Constitution of 1978.

Keywords: Spanish Navy, Spanish Constitution, human rights, fundamental rights, person's dignity.

Sumario: 1. INTRODUCCIÓN. 2. PRESUPUESTOS JURÍDICOCONSTITUCIONALES DE ACTUACIÓN. 3. FUNCIÓN DE POLICÍA DE LA ARMADA. 4. USO DE LA FUERZA: ATAQUE, ABORDAJE Y REGISTRO DE LA NAVE. A) Introducción. B) Límites genéricos: principio de necesidad y proporcionalidad en el uso de la fuerza. C) Legítima defensa y ataque. D) Abordaje y registro de la nave. a) Procedimiento de ejercicio. b) Neutralización de la tripulación contraria. c) Inspección de cámaras «aptas para la vida íntima» del buque. d) Competencia de los miem- 
bros de la Policía Naval para la práctica de la diligencia. e) Practica de la diligencia. E) Incautación y hundimiento. 5. PAUTAS EN ORDEN A LA DETENCIÓN DE SOSPECHOSOS. A) Introducción. B) Retención a los solos efectos de ejercicio del derecho de visita. C) Detención. D) Plazo de detención. E) Libro-registro de detenidos. F) Derechos del detenido. a) Garantía de información al detenido. b) Derecho a no ser obligado a declarar.

c) Derecho a asistencia de un abogado. d) Derecho a comunicar el hecho de la detención. e) Derecho a interponer recurso de habeas corpus.

\section{INTRODUCCIÓN}

Resulta fácil imaginar hasta qué punto una nueva situación como era la reaparición del fenómeno de la piratería en el mar, cuyos efectos se han hecho sentir para nuestro país sobre todo desde el secuestro del atunero Playa de Bakio en abril de $2008^{1}$, en escalada creciente desde entonces, tuviera que dar lugar también a problemas importantes en orden a su tratamiento jurídico.

La progresión en la participación en misiones internacionales, principal novedad a la que tuvieron que hacer frente las FF.AA desde 1989, en cumplimiento de nuestras obligaciones respecto a las Naciones Unidas o como miembro de la UE o de la OTAN, ha hecho y hace necesario el estudio continuado de vías jurídico-políticas para tratar de hacer aún más compatible la intervención en operaciones de carácter militar no sólo dentro de los mínimos establecidos por el «Derecho Internacional de los Conflictos Armados», sino, más allá, procurando el mayor nivel de cumplimiento de los derechos fundamentales dentro del marco de garantía reconocido por nuestra Constitución y nuestro régimen jurídico.

Especial importancia presenta, en este ámbito material, la garantía de unos derechos mínimos de los prisioneros y detenidos en este tipo de operaciones. La articulación de institutos de protección de nivel internacional, como es el caso del Convenio de Ginebra de 1949, relativo al trato de prisioneros de guerra, o la aparición a nivel nacional de disposiciones normativas que precisan expresamente el deber del militar de respetar la dignidad de la persona y los derechos fundamentales reconocidos en la Constitución, como el Real Decreto 96/2009, de 6 de febrero, por el que se aprueban las Reales Ordenanzas para las FF.AA, por poner dos ejemplos significativos; la configuración de unos determinados supuestos punibles que cifran como delito actos como atentar contra la vida, la integridad del prisionero o el infringirle cualquier tipo de trato inhumano (artículos 69, 71, 76 y 78 de la Ley Orgánica 13/1985, de 9 de diciembre, de Código Penal Militar), son algunas de las muestras del

\footnotetext{
${ }^{1}$ Sobre las vicisitudes de este hecho, véase la comparecencia del Ministro de Asuntos Exteriores ante la Comisión del Congreso de Asuntos exteriores, para informar sobre las actuaciones llevadas a cabo por el Gobierno en relación con el secuestro del pesquero «Playa de Bakio», en Diario de Sesiones del Congreso de los Diputados, n. . 27, año 2008, pp. 30-33.
} 
alcance que ha cobrado esta cuestión en los Estados constitucionales modernos, pero también de la necesidad de promover revisiones legislativas para prever vías de actuación ante las situaciones nuevas que se vayan sucediendo lo más ajustadas al marco de garantías establecido por los Tratados internacionales y la Constitución española y evitar -en la medida de lo posible- la improvisación en cuestiones tan delicadas como son la protección de la dignidad de la persona y los derechos fundamentales.

La importancia que, cada vez más, va tomando esta necesidad, puede también entreverse muy bien recordando algunas de las misiones en las que han tenido que participar las FF.AA en los últimos años, que han sido particularmente intensas y en las que se tuvieron que tomar prisioneros. Piénsese, por ejemplo, es el caso del incidente de la isla de Perejil en el año $2002^{2}$ o en la intervención española en el conflicto de Irak ${ }^{3}$. Ahora bien, la problemática que se suscita ante la necesidad de profundización en el nivel mínimo de garantías para la protección del prisionero o detenido por acción de las FF.AA quizás no se perciba con tanta claridad como en el caso de detención tras el abordaje de un buque pirata en alta mar. Por un lado, ya que, por ahora, no se ha perfilado un marco jurídico que regule exhaustivamente la posible función de policía de la Armada, que determine las condiciones de detención y privación de libertad -aunque sea temporal- a bordo de un buque militar y hasta qué punto puede el Comandante al mando de la nave imponer medidas de restricción de derechos individuales por razones excepcionales de seguridad a bordo. Y, por otro lado, porque la Acción Común 2008/851/PESC del Consejo, de 10 de noviembre, relativa a la Operación Militar de la UE para contribuir a la disuasión, prevención y represión de los actos de piratería en las costas de Somalia ${ }^{4}$, abre la posibilidad de que el ejercicio de la jurisdicción y el en-

\footnotetext{
${ }^{2}$ En este caso, según la comparecencia del entonces Ministro de Defensa, el Sr. Trillo Figueroa y Martínez-Conde, se procedió, sin necesidad de enfrentamiento alguno, a la «retención» de los seis militares marroquíes capturados, que fueron tratados de acuerdo con las instrucciones con el máximo respeto que exigía su condición militar y entregados a las pocas horas a las autoridades marroquíes a través de los puestos fronterizos de Ceuta por la Delegación del Gobierno. Diario de Sesiones del Congreso de los Diputados, n. ${ }^{\circ}$ 543, año 2002, pp. 17349 y ss.

${ }^{3}$ Hoy se sabe que «en Irak hubo 111 detenidos, de los cuales se entregaron 78 a la policía iraquí y 33 al Centro de Confinamiento de Bagdad, siguiendo el procedimiento para ello. No habiéndose recibido de ningún organismo internacional queja de soldado español alguno por haber vulnerado los derechos humanos». Véase «Contestación del Gobierno sobre personas detenidas por las tropas españolas en Irak y en Afganistán posteriormente puestas a disposición de las tropas estadounidenses» en Boletín Oficial de las Cortes Generales, Congreso de los Diputados, n. ${ }^{\circ}$ 386, Serie D, 16 de mayo de 2006, p. 207.

${ }^{4}$ Acción común 2008/851/PESC del Consejo, de 10 de noviembre del 2008, relativa a la Operación Militar de la Unión Europea destinada a contribuir a la disuasión, prevención y represión de los actos de piratería y del robo a mano armada en las costas de Somalia ( $D O \mathrm{~L}$ 301, de 12 de noviembre de 2008).
} 
juiciamiento de los detenidos por actos de piratería ceda ante un tercer Estado que la ejerza en lugar del Estado del buque que realiza la detención. El tercer país, de conformidad con el denominado «Canje de notas entre la UE y el Gobierno de Kenia sobre las condiciones de entrega de personas sospechosas de haber cometido actos de piratería» ${ }^{5}$, es la República de Kenia. Y, de esta suerte, los piratas detenidos por la European Union Naval Force (EUNAVFOR) pueden ser desembarcados en las costas de Kenia, a efectos de que sean los órganos judiciales de este país los que procedan a su enjuiciamiento. Con lo cual, la cuestión del grado de respeto de los derechos humanos, eficacia de garantía de tutela judicial e incluso la situación de las cárceles del tercer país, se convierte por necesidad en una base para evaluar la conveniencia de tal eventualidad.

Si se parte de los casos concretos en los que la Armada ha tenido que proceder a la detención de piratas en el marco de la «Operación Atalanta», en el Golfo de Adén o en el Índico, también se pueden observar muy bien las complejidades que revisten este tipo de situaciones. En primer lugar cabe recordar cómo el Buque Marqués de la Ensenada, los días 6 y 7 de mayo de 2009, detuvo catorce piratas y las dificultades jurídicas que se suscitaron posteriormente. En este caso, siguiendo el artículo 23.4 (c) de la Ley Orgánica del Poder Judicial y el artículo 100 del Convenio de las Naciones Unidas sobre el Derecho del Mar de 1982, a tenor de los cuales la jurisdicción española podría tener competencia para conocer de los hechos realizados por españoles o extranjeros fuera del territorio nacional susceptibles de tipificarse como piratería, el Juez competente de la Audiencia Nacional entendió -con el informe favorable del Fiscal- que podían ser enjuiciados y, en su caso, encarcelados en España, imputándoles los delitos de detención ilegal, robo con violencia y empleo de armas (artículos 163 y 242 del Código Penal, respectivamente). El Fiscal cambió después de posición y, sobre la base del citado Canje de notas entre la UE y el Gobierno de Kenia, solicitó la puesta en libertad de los detenidos a efectos de su posterior entrega a las autoridades de Nairobi. Lo que se traduciría luego en el hecho de que, puesto que nadie instó la prisión provisional (artículo 505.4 de la Ley de Enjuiciamiento Criminal), el Juez se viera forzado a decretar su libertad provisional, aunque sin exigir el traslado de los detenidos a Kenia ${ }^{6}$. En consecuencia el Fiscal y la Abogacía del Estado procedieron a redactar sus recursos para evitar la puesta en libertad de los piratas y conseguir su entrega a las autoridades de Kenia. Como contrapartida,

\footnotetext{
${ }^{5}$ Canje de Notas entre la Unión Europea y el Gobierno de Kenia sobre las condiciones y modalidades de entrega de personas sospechosas de haber cometido actos de piratería y detenidas por la fuerza naval EUNAVFOR dirigida por la UE, así como de las propiedades incautadas en posesión de EUNAVFOR, de EUNAVFOR a Kenia y con vistas a su trato después de su entrega, de 6 de marzo de 2009 (DO L 79, de 25 de marzo de 2009).

${ }^{6}$ Auto del Juzgado Central de Instrucción n. ${ }^{\circ} 4$ de la Audiencia Nacional de 8 de mayo de 2009.
} 
en el intento de solventar la contradicción entre la liberación de los inculpados y la operatividad de la contribución española a la seguridad en la zona, e impedir que quedasen impunes los actos ilícitos realizados, el Juez, in extremis, dictaría providencia autorizando la entrega de los detenidos a las autoridades de Kenia ${ }^{7}$. No hace falta precisar más los hitos legales a través de los cuales se desarrollo este procedimiento. Lo que importa señalar es que, desde que fueron detenidos hasta que fueron puestos a disposición de la policía de Mombasa, el 17 de mayo de 2009, los piratas somalíes pasaron trece días retenidos en el buque, sin que se supiera cómo se podían hacer efectivas las mínimas garantías reconocidas en el artículo 17 de la Constitución y, por extensión, del artículo 520 de la Ley de Enjuiciamiento Criminal. Además, en este caso, se dio la circunstancia de que uno de los detenidos se lesionó por un golpe en el momento de la detención.

En segundo lugar hay que citar el secuestro del pesquero español Alakrana, el día 3 de octubre de 2009, y la detención posterior por soldados de Infantería de Marina de dos de los piratas implicados. La primera y decisiva diferencia con el caso anterior es que ahora se trataba de un ataque a un buque español y de un secuestro a ciudadanos españoles, lo que suponía que la Audiencia Nacional tenía plena jurisdicción para procesar a los detenidos (artículos 65.1.e y 88 de la Ley Orgánica del Poder Judicial). No vamos a discutir aquí la oportunidad de la detención de estos piratas, cuestión a la que la Armada estaba obligada según las propias normas de actuación de la Operación internacional ${ }^{8}$, ni tampoco los motivos del Juez competente para abrir diligencias y ordenar su traslado a España, justificada, en definitiva, sobre la base de la denuncia presentada por la Abogacía del Estado y la petición de prisión para los dos somalíes que realizó la Fiscalía ${ }^{9}$. Importa, no obstante, apuntar

\footnotetext{
${ }^{7}$ En la providencia dictada, el magistrado-juez de la Audiencia Nacional, especificaba que «el Auto dictado en la presente causa de fecha de 8 de mayo de 2009 no impide el desembarco de los inculpados en Kenia o en cualquier otro punto que, por el Comandante de la Fuerza Naval o la Autoridad competente que corresponda, se considere que reúne las condiciones de seguridad y operatividad que consideren necesarias» (Providencia del Juzgado Central de Instrucción n. . 4 de la Audiencia Nacional de 11 de mayo de 2009).

${ }^{8}$ En cumplimiento del Artículo 2 de la Acción común 2008/851/PESC del Consejo de la UE. Véase también la comparecencia de la vicepresidencia del Gobierno para informar sobre las actuaciones llevadas a cabo para la liberación del buque Alakrana. Diario de Sesiones del Congreso de los Diputados, n. ${ }^{\circ} 126$, de 25 de noviembre de 2009, pp. 34 y 35.

${ }^{9}$ «La actuación del Juez Central se realizó en el marco de la más estricta legalidad, como Juez de Guardia y en respuesta a una denuncia presentada por la Abogacía del Estado, sin actuar de oficio. Ni el Juez de Guardia ni el Juzgado instaron a organismo alguno para que las personas fueran trasladadas a España, sino que cumplió con la ley al ordenar su traslado para legalizar la situación de las mismas, una vez les constó su detención». Véase así la «Nota Informativa de la Presidencia de la Audiencia Nacional en relación a la actuación procesal del Magistrado Juez Baltasar Garzón Real en el asunto del pesquero Alakrana», de 12 de noviembre de 2009.
} 
dos circunstancias muy singulares que dificultaron la puesta a disposición judicial efectiva de los detenidos. Por un lado, por la propia complejidad y la duración del traslado (una semana), para lo que se requirió, además, de la colaboración de buques de otros países de la coalición. Y, por otro lado, porque, una vez en España, uno de los piratas alegó ser menor de edad. Por lo que se le tuvo que realizar previamente un examen forense en un Hospital a efectos de determinar si el pirata somalí era o no mayor de edad. La problemática, además, se agravaría desde el momento en que el informe médico afirmó, pero sin absoluta certeza, que el implicado tenía 18 años. Así las cosas, el Juez Central de Menores de la Audiencia Nacional -al entender que el sujeto era mayorplanteó cuestión de competencia negativa a favor del Juez del Juzgado Central de Instrucción n. ${ }^{\circ} 1$ de la Audiencia Nacional. Lo que se tradujo después en el hecho de que, puesto que no había pruebas que certificaran sin lugar a dudas la mayoría de edad del detenido, el Juez del Juzgado Central de Instrucción devolviera otra vez la causa al Juez Central de Menores, al aplicar el principio in dubio pro reo, a saber: «caso de que existan dudas sobre la edad, éstas se resolverán a favor de la minoría de edad» ${ }^{10}$. Como solución a este nuevo problema en orden a la determinación de la competencia, se pidió un nuevo dictamen médico a efectos de determinar indubitadamente la edad del detenido y se decretó su ingreso en un Centro de Menores hasta que la propia Audiencia Nacional estableciera que juzgado debía conocer los hechos. Tras el nuevo informe forense, presentado el 2 de noviembre de 2009, se certificó la mayor edad penal del imputado, declarando la Sala de lo Penal de la Audiencia Nacional ${ }^{11}$ la competencia definitiva del Juzgado Central de Instrucción n. ${ }^{\circ} 1$ de la Audiencia Nacional para investigar la conducta atribuida al sospechoso.

Las dificultades de este caso se observan sobre todo en orden a las dilaciones y la incertidumbre respecto a la situación procesal del detenido. No obstante, hay que tener en cuenta otro aspecto: la jurisdicción del Juzgado de Menores de la Audiencia Nacional. En realidad, la competencia de ese órgano se reduce a situaciones de menores de edad que están acusados de terrorismo (artículo 2.4 de la Ley Orgánica 5/2000, de 12 enero, reguladora de la responsabilidad penal de menores) $)^{12}$. En el caso de que el pirata somalí, final-

${ }^{10}$ SSTS de 25 de junio de 1965, 14 de enero de 1988, 18 de mayo de 1992 y 24 de septiembre de 1992. Cfr. Auto del Juzgado de Instrucción n. ${ }^{\circ} 1$ de la Audiencia Nacional de 23 de octubre de 2009.

${ }^{11}$ Auto de la Sala de lo Penal de la Audiencia Nacional de 2 de noviembre de 2009.

${ }^{12}$ En principio, en el caso expuesto, la competencia sobre la investigación de los hechos hubiera podido recaer en el Juez de Menores del lugar donde se hubieran realizado los hechos delictivos, de conformidad con el artículo 2.3 de la Ley 5/2000, de 12 de enero, reguladora de la responsabilidad penal de menores. Ahora bien, la Fiscalía de Menores de Madrid declinó hacerse cargo de los hechos por cuanto éstos se habían realizado en el extranjero. Así las cosas, la Fiscalía de Menores de la Audiencia Nacional entendió que, dado que los hechos se habían realizado en el extranjero, la competencia podía ser asumida por el Juzgado de Menores de la Audiencia Nacional. 
mente, hubiera sido realmente menor de 18 años, la asunción de competencia por el Juzgado de Menores de la Audiencia Nacional, como solución de compromiso, hubiera podido suponer la ilegalidad de la detención. Hay que recordar que la práctica de actos de investigación que afecten a los derechos fundamentales, caso de que el detenido sea menor, está muy matizada por la Ley Orgánica 5/2000. Pero es que, además, es regla típica, que el órgano judicial llamado a conocer de los hechos debe estar «investido de jurisdicción y competencia antes del hecho que motive su actuación $»^{13}$. Teniendo en cuenta, por tanto, el vacío jurídico de esta materia y la posibilidad de que las FF.AA se vean obligadas en algún otro caso a proceder a la detención de «niños soldado», es conveniente que el legislador realice las revisiones o previsiones normativas necesarias a efectos de evitar situaciones de improvisación como la descrita.

Las consecuencias de la improvisación se muestran también cuando se mira más allá de nuestras fronteras, en el marco europeo. Recuérdese, por ejemplo, el caso del abordaje de dos barcos y la detención de 10 piratas, el 17 de diciembre de 2008, por el buque danés HDMS Absalon, integrante de la fuerza marítima Combined Task Force 150. De conformidad con la legislación danesa, a tenor de la cual está prohibida la extradición a países en los que el inculpado pueda ser condenado a muerte o sometido a tortura, las autoridades judiciales de ese país determinaron que los detenidos no podían ser entregados a Somalia ni a ninguno de los países limítrofes y que, por tanto, debían ser procesados en Dinamarca. No obstante, al mismo tiempo se sopesaron las dificultades de deportar a los piratas tras el cumplimiento de condena y, tras seis días de detención, la idea de enjuiciamiento en Dinamarca sería reemplazada por una simple y rápida puesta en libertad de los sospechosos en una playa de Somalia ${ }^{14}$. Piénsese que también, el 25 de diciembre de 2008, la fragata alemana Karlsruhe procedió a la detención de unos piratas que habían atacado a un carguero egipcio y que, posteriormente, fueron igualmente puestos en libertad ante la incertidumbre del posible enjuiciamiento en Alemania y las dificultades de deportación de los sujetos a su país tras el cumplimiento de la condena ${ }^{15}$. El nexo común que se observa en estos ejemplos es la cuestión de que la falta de una legislación interna clara sobre la adopción de disposiciones respecto a los piratas después de que han sido capturados ha impedido que se tomen medidas realmente eficaces para atajar el problema ${ }^{16}$. Más, de-

\footnotetext{
${ }^{13}$ SSTC 47/1983; 101/1984 y 147/1987. A mayor abundamiento, también cabe recordar que «una eventual irregularidad en la designación del Juez que debe entender de un proceso puede constituir una infracción del derecho del justiciable al Juez predeterminado por la ley del artículo 24.2 de la Constitución» (STC 31/1983).

${ }^{14}$ Cit. en TREVES, T., «Piracy, Law of the Sea, and Use of Force: Developments off the Coast of Somalia», en The European Journal of International Law, Vol. 20, n. 22, 2009, p. 408.

${ }^{15}$ Sobre ello y la polémica a que dio lugar, véase «Grüne und FDP kritisieren Freilassung von Piraten», en el rotativo Frankfurter Alllgemeine Zeitung, 29 de diciembre de 2008.

${ }^{16}$ Resolución 1851 del Consejo de Seguridad de la ONU, de 16 de diciembre de 2008.
} 
trás de ello, está también la problemática de que los Estados, como ha destacado Treves, no están del todo dispuestos a someter a un procedimiento penal ante sus tribunales de justicia a los piratas ${ }^{17}$. El hecho de que el delito se haya realizado en un lugar tan lejano y la difícil consecución del procedimiento con todas las garantías; de una parte la dificultad de llevarlo a cabo en un plazo razonable y de implementar el derecho de defensa; de otra las dificultades en orden a la investigación, la obtención de pruebas o de asegurar la presencia de testigos, apuntan a un encarecimiento del proceso que los Estados no están dispuestos a asumir en todo caso. También la posibilidad de que los piratas opten por permanecer en el país tras el cumplimiento de la condena o realicen peticiones de asilo son temores que agravan la solución de este fenómeno.

\section{PRESUPUESTOS JURÍDICO-CONSTITUCIONALES DE ACTUA- CIÓN}

No establece nuestra Constitución, a diferencia de lo que ocurre, por ejemplo, en la Ley Fundamental alemana ${ }^{18}$, ningún tipo de requisito explícito en orden a la participación de las FF.AA en misiones internacionales. La cláusula del artículo 8.1 de la Constitución, aparte de mencionar su función de garantía de la soberanía e independencia de España, su integridad territorial y el orden constitucional, «no limita taxativamente el ámbito de actuación de los Ejércitos» ${ }^{19}$. Sin embargo, el artículo 8.2 de la Constitución, desvía la posibilidad de delimitación de esta cuestión al legislador a través de ley orgánica. En estas circunstancias, y de acuerdo a la Constitución y la vigente Ley Orgánica 5/2005, de 17 de noviembre, de la Defensa Nacional, se puede decir que la intervención militar actual en misiones internacionales se articula sobre la base de dos pilares fundamentales: por un lado, en cumplimiento de ciertas obligaciones internacionales, que «encuentra su fundamento último en la voluntad de la Nación de colaborar en el fortalecimiento de unas relaciones pacíficas entre todos los pueblos de la tierra» (Preámbulo) ${ }^{20}$; por otro lado,

${ }^{17}$ TREVES, T., «Piracy, Law of the Sea...», cit., p. 408.

${ }^{18}$ El artículo 87.a.2 de la Ley Fundamental establece que «fuera de la defensa, las Fuerzas Armadas podrán utilizarse, sólo cuando así lo autorice expresamente la presente Ley Fundamental». En Alemania la participación en la Operación Atalanta se sostiene, por un lado, en el mandato de la Unión Europea y, además, en las resoluciones de las Naciones Unidas, por otro lado, en el propio artículo 24. 2 de la Ley Fundamental, que afirma que «la Federación puede adherirse a un sistema de seguridad colectiva mutua». Casi en estos mismos términos, WIEFELSPÜTZ, D., «Die Beteiligung der Bundeswehr am Kampf gegen Piraterie», en Neue Zeitschrift für Wehrrecht, 2009, 4, pp. 136 y 137.

${ }^{19}$ LÓPEZ RAMÓN, F., La caracterización jurídica de las Fuerzas Armadas, Centro de Estudios Constitucionales, 1987, 1987, p. 328.

${ }^{20}$ FERNÁNDEZ SEGADO, F., «El estatuto jurídico-constitucional de las Fuerzas Armadas y su desarrollo legislativo. Balance de un cuarto de siglo», en Revista Española de Derecho Constitucional, n..$^{\circ}$, Centro de Estudios Políticos y Constitucionales, Madrid, 2004, p. 196. 
en el principio democrático, por cuanto corresponde al Congreso de los Diputados, de conformidad con los artículos 4.2 y 17 de la Ley 5/2005, de 17 de noviembre, de la Defensa Nacional, decidir o «autorizar, con carácter previo, la participación de las FF.AA en misiones fuera del territorio nacional» ${ }^{21}$.

En primer lugar, el deber de cumplimiento de las obligaciones internacionales, desde la perspectiva del tema objeto de estudio, en el plano jurídico positivo, se puede derivar de normas de rango internacional como el Convenio de Ginebra de 1948 sobre Alta Mar, de 29 de abril de $1958^{22}$, y la Convención de las Naciones Unidas sobre el Derecho del Mar, hecho en Montego Bay, de 30 de abril de 1982 (Convenio de Jamaica) ${ }^{23}$, por las que se determina la obligación de «todos los Estados de cooperar en la medida de lo posible en la represión de la piratería en la alta mar o en cualquier otro lugar que no se halle bajo la jurisdicción de ningún Estado» (artículos 14 y 100, respectivamente). La validez y eficacia de estos textos deviene de su ratificación y publicación en el ordenamiento interno, en los términos del artículo 96.1 de la Constitución. Es indiscutible, por tanto, que estos documentos internacionales bastan, como elemento legitimador de la intervención militar. Pero, por otra parte, esta posibilidad se ha fortalecido desde que las Naciones Unidas han aprobado la Resoluciones 1816,1846 y $1851^{24}$, como consecuencia del agravamiento progresivo de la piratería sobre todo en el Golfo de Adén y en Somalia ${ }^{25}$. Las razones que justifican la intervención militar por parte del Consejo de Seguridad son claras: evitar el robo a mano armada de buques de transporte de ayuda humanitaria a la zona y asegurar las rutas comerciales marítimas y la navegación internacional. Por otro lado, de forma paralela, la Unión Europea ha emprendido una acción militar en apoyo de las Resoluciones 1816, 1846 y 1851 del Consejo de Seguridad de las Naciones Unidas, denominada Atalanta, con los mismos fines (Acción Común 2008/851/PESC del Consejo) ${ }^{26}$.

${ }^{21}$ Sobre ello, en detalle, CALAFELL FERRÁ, V., «Cortes Generales y misiones militares en el exterior: la autorización del Parlamento para enviar tropas españolas al extranjero», en Isidro SEPÚLVEDA (Edit.), España en las operaciones internacionales de pacificación, Instituto Universitario General Gutiérrez Mellado-UNED, Madrid, 2009, pp. 379-392.

${ }^{22}$ BOE n. ${ }^{\circ} 309$, de 27 de diciembre de 1971, pp. 20. 994-20.997.

${ }^{23} B O E$ n. ${ }^{\circ} 39$, de 14 de febrero de 1997, pp. 4.996-5.055.

${ }^{24}$ Resolución 1816 del Consejo de Seguridad de la ONU, de 2 de junio de 2008, Resolución 1846 del Consejo de Seguridad de la ONU, de 2 de diciembre de 2008 y Resolución del Consejo de Seguridad de la ONU, de 16 de diciembre de 2008.

${ }^{25}$ Véanse estadísticas y porcentajes recientes en Piracy and Armed Robbery Against Ships. Annual Report 2008, ICC. International Maritime Bureau, Londres, 2009, pp. 5-22; Piracy and Armed Robbery Against Ships. Report for the Period 1. January-30. September 2009, ICC. International Maritime Bureau, Londres, 2009, pp. 6-22. Documentos disponibles en http://icc-ccs.org

${ }^{26}$ El marco jurídico básico de la intervención también se halla delimitado por la Acción común 2008/749/PESC, del Consejo, de 19 de diciembre de 2008, relativa a la acción de coordinación militar de la Unión Europea en apoyo de la Resolución n. ${ }^{\circ} 186$ (2008) del Consejo de Seguridad de las Naciones Unidas (EU NAVCO) (DO L 252, de 20 de septiembre de 2008). 
En segundo lugar, la implementación del principio democrático en orden a las intervenciones militares en el extranjero ha supuesto la introducción de dos novedades en nuestro ordenamiento jurídico: por un lado, la obligación de que la participación de las FF.AA fuera del territorio nacional sea la manifestación de la voluntad de la mayoría del Congreso de los Diputados; por otro lado, supone una limitación de las facultades del Gobierno en su función de dirección de la política de defensa ${ }^{27}$ (artículo 97 de la Constitución). Ya en Alemania, el Tribunal Constitucional Federal, en su decisión de 12 de julio de 1994, entendió que toda misión de las Fuerzas Armadas requiere de la aprobación previa del Bundestag ${ }^{28}$. A la misma concepción responde la consideración de las FF.AA como «ejército del Parlamento, integrado en el orden constitucional estatal democrático» ${ }^{29}$. En esta misma línea, en el marco de las operaciones internacionales, se encuadra la Ley 5/2005, de 17 de noviembre, de la Defensa Nacional. Y, en cumplimiento de este requisito, encontramos la Solicitud de autorización del Congreso de los Diputados, de 21 de enero de 2009, para la participación de un contingente militar español en la «Operación Atalanta» de la Unión Europea para luchar contra la piratería en aguas de Somalia ${ }^{30}$.

En términos generales cabría entender la Convención de las Naciones Unidas sobre el Derecho del Mar de 1982, como se ha dicho, elemento legitimador del uso de la fuerza para represión de la piratería y, en su caso, la detención y enjuiciamiento de piratas. Ya Kelsen destacó el carácter obligatorio, en el caso excepcional de la piratería, de las normas de Derecho internacional en el mismo nivel de las normas de Derecho interno. Kelsen llega a propugnar, en este caso particular, la innecesariedad de una norma penal de Derecho nacional que trasponga el mandato internacional. La obligatoriedad de la represión de la piratería se basa aquí en el carácter especial del ilícito y la facultad del Estado de actuar como «órgano de la comunidad internacional». «El principio nulla poena sine lege -llega a escribir Kelsen- sería respetado incluso en ausencia de una norma de derecho nacional, ya que existe una norma internacional que autoriza a castigar al pirata ${ }^{31}$. Siguiendo esta línea, considerando la piratería como un delito especialmente contrario a un «sistema de valores internacionales comunes» ${ }^{32}$, entre nosotros, algunos au-

${ }^{27}$ CALAFELL FERRÁ, V., «Cortes Generales y misiones militares...», cit., p. 391.

${ }^{28}$ BVerfGE 90, 286 (381).

${ }^{29}$ Ibídem.

${ }^{30}$ Sometida a votación la solicitud de autorización, se aprobó por una mayoría de 311 votos a favor y dos abstenciones. Diario de Sesiones del Congreso de los Diputados, $\mathrm{n}$. 58 , 2009, pp. 2-17.

${ }^{31}$ KELSEN, H., Teoría general del Derecho y del Estado, Universidad Nacional Autónoma de México, México D.F., 1995, pp. 409 y 410. Traducción de Eduardo García Máynez.

${ }^{32}$ LUCCHINI, L. / , VOELCKEL, M., Droit de la Mer, Vol. I, Pedone, Paris 1990, p. 292. 
tores (Corrales Elizondo ${ }^{33}$, Ollé Sesé ${ }^{34}$ ) también han apuntado que, con una interpretación amplia del artículo 100 de la Convención de las Naciones Unidas, podría comprenderse la piratería en el mar como un delito contra la comunidad internacional perseguible por todos los países de acuerdo al principio de jurisdicción penal internacional y que, por tanto, podrían conocer nuestros tribunales de los delitos de piratería cometidos tanto por súbditos españoles como extranjeros.

No obstante, hay que tener en cuenta el carácter fundamental en el ordenamiento constitucional moderno del principio de legalidad penal, que presupone la delimitación previa en la norma de las conductas punibles y las consecuencias jurídicas de su comisión. De hecho, la regulación de la piratería está prevista en algunos Estados constitucionales con diversa intensidad y grado. Así, mientras que en Estados Unidos se contempla directamente en la Constitución la facultad del Congreso «para definir y castigar la piratería y otros delitos cometidos en alta mar» (artículo 1. Sección 8) ${ }^{35}$, en Inglaterra se considera como «una ofensa ipso facto al Derecho inglés» ${ }^{36}$, quedando expresamente tipificada como delito por el Piracy Act ${ }^{37}$. Alemania, por otro lado, recoge esta forma delictiva de forma no expresa, bajo el rótulo «ataques en la seguridad del tráfico marítimo» (\$ 316.c del Strafgesetzbuch) ${ }^{38}$. También nuestro Código penal de 1973 sancionaba directamente, en su artículo 138, «el delito de piratería cometido contra españoles o súbditos de otra nación» con una pena de reclusión mayor ${ }^{39}$.

\footnotetext{
${ }^{33}$ CORRALES ELIZONDO, A., Soluciones jurídicas en relación a la piratería y otros delitos graves en la mar, pp. 10 y 11 Disponible en red en http://www.asesmar.org/

${ }^{34}$ OLLÉ SESÉ, M., Justicia universal para crímenes internacionales, La Ley-Universidad Nebrija, Madrid, 2008, pp. 107-111,355-359.

${ }^{35}$ El Congreso ha llegado a implementar este tipo de obligación internacional. Véase, así, por ejemplo, el U.S. Code, Título 18, Parte I, Capítulo 81-\$1651 (1996), cuando dice que «todo aquél que, en alta mar, cometa el delito de piratería y sea detenido o encontrado en los EE.UU., será castigado con la pena de cadena perpetua».

${ }^{36}$ LOWE, V., «The United Kingdom and the Law of the Sea», en TREVES T. y PINESCHI, L., (Edit.), The Law of the Sea: The European Union and its members states, Martinus Nijhoff Publisher, Países Bajos, 1997, p. 545.

${ }^{37}$ Véase, Piracy Act 1837, Capítulo 88, donde se establece que «todo aquél que con intención de cometer, bien sea en los prolegómenos o después de la comisión, el delito de piratería contra un barco o embarcación, ataque con intención de matar a alguna de las personas de a bordo o que forme parte de la tripulación, ataqué con arma blanca o hiera a cualquier persona o realice algún tipo de acto ilegal por el que ponga en peligro la vida de personas, será culpable de delito grave».

${ }^{38}$ Este artículo establece una pena privativa de libertad no inferior a cinco años para todo aquél que utilice violencia, constriña la libertad individual de la persona o realice cualquier acto destinado a conseguir tomar o influir en el mando de un barco de transporte marítimo civil.

${ }^{39}$ Decreto 3096/1973, de 14 de septiembre, por el que se publica el Código Penal, texto refundido conforme a la Ley 44/1972, de 15 de noviembre (Libro II, Título I, Capítulo IV [Art. 138 y 139]).
} 
En este contexto, encontramos la regulación actual de este fenómeno en nuestro ordenamiento jurídico vigente. Hay que decir que el artículo 23.4(c) de la Ley Orgánica 6/1985, de 1 de julio, del Poder Judicial reconoce la competencia de la «jurisdicción española para conocer de los hechos cometidos por españoles o extranjeros fuera del territorio nacional susceptibles de tipificarse, según la ley española» como piratería, se podría entender, de conformidad con ello, que nuestro tribunales son efectivamente competentes para conocer de ese tipo de acto punible. Ahora bien, en tanto el Código penal de 1995 no tipificaba como acto punible la piratería y debido al carácter imperativo del principio de legalidad penal, recogido en el artículo 9.3 de la Constitución de 1978, que presupone que «nadie puede ser condenado o sancionado por acciones que en el momento de producirse no constituyan delito, falta o infracción administrativa, según la legislación vigente en aquel momento» (artículo 25.1 de la Constitución), no quedaba del todo claro cómo se podía implementar la atribución de jurisdicción del artículo 23.4 de la Ley 6/1985. Como solución a esta incoherencia y, en definitiva, para acomodar la normativa penal a nuestras obligaciones de Derecho internacional, el legislador ha aprobado la Ley Orgánica 5/2010, de 22 de junio, por el que se modifica la Ley Orgánica 10/1995, de 23 de noviembre del Código Penal. En este documento, se incluye en el Libro II, Título XXIV, un nuevo Capítulo V, bajo el título «Delito de piratería» ${ }^{40}$. Esta normativa no sólo se limita a tipificar como acto punible la piratería ${ }^{41}$, sino que también sanciona la mera desobediencia ante las indicaciones de un buque o aeronave militar con ocasión de la realización de operaciones o maniobras para la persecución o prevención de hechos de este tipo ${ }^{42}$. Y yendo más allá, también califica como sancionable la

${ }^{40}$ BOCG, Congreso de los Diputados, n. ${ }^{\circ}$ A.52-1, de 27 de noviembre de 2009, p. 40. Un análisis crítico de los preceptos relativos a la piratería del Anteproyecto puede verse en RODRÍGUEZ-VILLASANTE Y PRIETO, J., «La represión del crimen internacional de piratería; una laguna imperdonable de nuestro Código Penal y, ¿por qué no?, un crimen de la competencia de la Corte Penal Internacional», Real Instituto el Cano, n. $.^{\circ} 73,2009$, pp. 4 y 5. Disponible en red en http://www.realinstitutoelcano.org

${ }^{41} \mathrm{El}$ artículo 616 ter se expresa con el siguiente tenor: «El que con violencia, intimidación o engaño, se apodere, dañe o destruya una aeronave, buque u otro tipo de embarcación o plataforma en el mar, o bien atente contra personas, cargamento o bienes que se hallaren a bordo de las mismas, será castigado con la pena de prisión de diez a quince años. En todo caso, la pena prevista en este artículo se impondrá sin perjuicio de las que corresponda por los delitos cometidos».

${ }^{42}$ El nuevo artículo 616 quáter se expresa con el siguiente tenor: «1.- El que con ocasión de la prevención o persecución de los hechos previstos en el artículo anterior, se resistiere o desobedeciere a un buque de guerra o aeronave militar $\mathrm{u}$ otro buque o aeronave al servicio del Estado español y esté autorizado a tal fin, será castigado con la pena de prisión de uno a tres años. 2.- Si en la conducta anterior se empleare fuerza o violencia se impondrá la pena de diez a quince años de prisión. 3.- En todo caso, la pena prevista en este artículo se impondrá sin perjuicio de las que corresponda por los delitos cometidos». 
conducta de todo aquel que, aún cuando no haya participado en la comisión del delito, intente, con posterioridad a su ejecución, ayudar -en los términos expuestos en el artículo 451 del Código Penal-a los presuntos responsables a eludir la investigación o sustraerse de su búsqueda y captura.

\section{FUNCIÓN DE POLICÍA DE LA ARMADA}

La base elemental que determina las funciones de las FF.AA es el artículo 8.1 de la Constitución. Conforme a este precepto, «el Ejército de Tierra, la Armada y el Ejército del Aire, tienen como misión garantizar la soberanía e independencia de España, defender su integridad territorial y el ordenamiento constitucional». Ahora bien, estas funciones -como ha enfatizado Oliver Araujo- no son las únicas que cumple la Armada y deben comprenderse en un sentido más amplio ${ }^{43}$. Cuando el artículo 8.1 de la Constitución asigna a la Armada la misión de proteger la integridad territorial y el orden jurídicoconstitucional del país, está apuntando a algo más que a estos fines genéricos de protección del Estado: por un lado, la defensa de la integridad territorial presupone, a la vez, la protección de los nacionales y de las comunicaciones e intereses marítimos y de la flota mercante, también en alta mar; por otro lado, la defensa del orden constitucional equivale a velar por el cumplimiento de las leyes y convenios internacionales en el ámbito marítimo ${ }^{44}$. Aparte, con base al principio de «cooperación internacional» (Preámbulo constitucional), se reconoce la asunción de labores de apoyo y participación en operaciones de asistencia humanitaria en casos de catástrofes o situaciones de emergencia en terceros países ${ }^{45}$.

El planteamiento señalado está, en ciertos aspectos, presente en la Ley Orgánica 5/2005, de 17 de noviembre, de la Defensa Nacional (artículos 15 y 16). Este texto desarrolla las funciones expresas de la Constitución y parece ampliar enormemente su campo de actuación, sobre todo en lo que se refiere a operaciones de mantenimiento de la paz y estabilización internacional. No vamos a entrar ahora en las razones que han llevado a realizar una reformulación de las funciones de las FF.AA, justificada, en definitiva, como deja entrever la Directiva de la Defensa Nacional 1/2008, en el hecho de que la pro-

${ }^{43}$ OLIVER ARAUJO, J., «El deber constitucional de defender a España», en FERNÁNDEZ SEGADO, F., (Edit.), El Servicio Militar: Aspectos jurídicos y socio-económicos, Dykinson, Madrid 1994, p.30.

${ }^{44}$ Compárese NÚÑEZ LACACI, F., y TORRENTE SÁNCHEZ, F., La Armada: Esa desconocida, San Martín, 1983, Madrid, pp. 115 y 116.

${ }^{45}$ Sobre este tipo de misiones, desde una perspectiva de Derecho internacional, véase, DE CASTRO SÁNCHEZ, C., Las acciones armadas por razones humanitarias ¿hacia una injerencia humanitaria? Una aproximación teórico-práctica, Ministerio de Defensa, Madrid, 2003, pp.127-139. 
tección a largo plazo de los valores y los derechos fundamentales reconocidos en nuestro ordenamiento jurídico requiere de un esfuerzo paralelo en orden a lograr un orden internacional estable y seguro ${ }^{46}$. Importa, no obstante, dejar constancia que esta interpretación de los fines primarios de las FF.AA del artículo 8.1 de la Constitución y su consecución ha requerido de una diversificación de sus obligaciones en caso de participación en operaciones en el extranjero. Servicio de apoyo logístico a proyectos de investigación científica, prestación de auxilio a victimas de catástrofes naturales, trasporte y distribución de ayuda humanitaria y reconstrucción de edificios se sitúan, así, también en parte de la actividad de la Armada, que no sólo debe establecer un entorno seguro a través de cometidos de protección y escolta, sino que debe ella misma participar en la provisión de ayuda humanitaria y reconstrucción de infraestructuras. La misión del BIO Las Palmas o del Hespérides en la Antártida, el envío del buque Galicia a Centroamérica para hacer frente a las consecuencias del huracán Mitch, en 1998, la misión «Respuesta solidaria» en Indonesia, con motivo del tsunami de 2005 y, más recientemente, el envío del buque Castilla a Haití, no hacen sino avalar el carácter polifuncional actual de la Armada ${ }^{47}$.

Es esta ampliación de las funciones de la Armada la que ha permitido plantear también la posibilidad de reafirmación de competencias policiales en teatros de operaciones como el del Golfo de Adén o el Índico, cuya última razón de ser habría que buscarla no sólo en el hecho de que se ha producido una progresiva difuminación de los límites entre seguridad interna y seguridad exterior, sino también en la dificultad de que puedan ser otros institutos (Policía o Guardia Civil) los órganos que puedan desarrollar una misión de estas características, en un espacio tan lejano y basto, que requiere un gran lujo de medios ${ }^{48}$. En este sentido, una eventual encomienda -como la de la Acción Común 2008/851/PESC, que permite la detención de personas sospechosas de haber cometido piratería (artículo 2.e)- de funciones típicamente policiales, es, desde nuestro punto de vista, factible ${ }^{49}$. De hecho, con inde-

${ }^{46}$ En sentido parecido, COTINO HUESO, L., El modelo constitucional de Fuerzas Armadas, Centro de Estudios Políticos y Constitucionales, Madrid, 2002, p. 112, quien habla de las nuevas funciones del Ejército como un «proceso de mutación de las operaciones militares clásicamente entendidas, y que permite crear un nexo causal que lleva, al fin y a la postre, a señalar misiones a miles de kilómetros vinculadas a la directa seguridad del Estado».

${ }^{47}$ Críticamente, pero justificando este tipo de misiones, como solución transitoria, en situaciones en las que las condiciones de seguridad estén muy deterioradas o en casos de imposibilidad de distribución de alimentos, agua, electricidad y sanidad. TAFALLA BALDUZ, A., «Soldados: ni miembros de ONG ni bomberos», en el diario El Mundo, 7 de enero de 2010, p. 17.

${ }^{48}$ PÉREZ RAMÍREZ, E., «Estrategias de Seguridad y Defensa», Conferencia pronunciada con motivo del Curso de experto en Seguridad y Defensa: Gestión de crisis y comunicación, en la Universidad Alfonso X el Sabio, el día 8 de enero de 2010.

${ }^{49}$ Una opinión en contrario en REGUEIRO DUBRA, R., «El uso de la fuerza en el mar y la Operación Atlanta de la Unión Europea», en el colectivo Crisis somalí, piratería e intervención internacional, Instituto Universitario General Gutiérrez Mellado, Madrid, 2009, p. 151. 
pendencia de que también cabe la alternativa de embarcar personal de la Policía Nacional o de la Guardia Civil para el desarrollo de ciertas operaciones ${ }^{50}$ y la tradicional labor de seguridad del buque o de la zona militar por parte del centinela, el Real Decreto 194/2010, de 26 de febrero, por el que se aprueban las Normas sobre seguridad en las FF.AA - que deroga el Tratado IV de las Reales Ordenanzas de la Armada- establece la posibilidad de que la Policía Naval desempeñe funciones de seguridad de cariz netamente policial, reconociendo expresamente su carácter de «agentes de la autoridad» en ejercicio de sus funciones (artículo 29.2) e, incluso, su capacidad para intervenir, en ausencia de Cuerpos y Fuerzas de Seguridad y dentro de los márgenes de la Ley de Enjuiciamiento Criminal, en caso de delito in fraganti (artículo 32). Además, establece que los cometidos que el ordenamiento jurídico asigna a la Policía Naval se pueden desempeñar en el ámbito de operaciones en el exterior. Pero es que, llegando más allá, de acuerdo a la Disposición adicional $1^{\mathrm{a}}$, se extiende a las propias dotaciones de los buques de la Armada el carácter de agentes de la autoridad en el ejercicio de funciones de vigilancia y seguridad marítima atribuidas legalmente o por convenios internacionales suscritos por España. Y, en fin, también cabe recordar aquí la Disposición adicional $3^{\text {a }}$ de la Ley 39/2007, de 19 de noviembre, de la Carrera Militar, que reconoce igualmente este carácter a los miembros de unidades de Policía Militar en el ejercicio de labores de colaboración con otras instituciones públicas en situaciones de «grave riesgo, catástrofe, calamidad u otras necesidades públicas».

En definitiva, las funciones que realizan los miembros de las FF.AA, o al menos una parte importante de ellos, son heterogéneas y exceden en algunos casos las labores de carácter estrictamente militar, a veces -sirvan aquí de ejemplo las funciones realizadas por los miembros de la Armada en el marco de la Operación Atalanta-excesivamente similares a las realizadas por las Fuerzas y Cuerpos de Seguridad del Estado. En este contexto, hay que destacar las funciones de tipo policial y seguridad pública de la Policía Militar. Es por esto que sería conveniente un marco legal más pormenorizado de sus límites de actuación ${ }^{51}$. A tal efecto el novísimo Real Decreto 194/2010, de 26 de febrero, se presenta ralo y escueto. Si este tipo de unidades especiales no

\footnotetext{
${ }^{50}$ Recuérdese aquí, por ejemplo, el reciente caso del Destiny Empress, buque oceanográfico de bandera desconocida que fue capturado en alta mar, cerca de Canarias, por el buque de la Armada Serviola, el día 20 de diciembre de 2009. El abordaje se produjo por miembros de los GEO de la Policía Nacional que habían sido embarcados previamente para la realización de la maniobra.

${ }^{51}$ En este sentido, TAFALLA BALDUZ, A., «¿Policías o militares?» en el diario $E l$ Mundo, 19 de noviembre de 2009, p. 27, para quien «se debería crear un marco jurídico adecuado para cuando nuestros marinos y soldados son enviados a combatir en conflictos de guerra irregular (...), que incluyera cómo tratar a nuestros enemigos que no tienen los rasgos tradicionales del soldado combatiente».
} 
sólo realizan misiones de protección de instalaciones militares, sino también operaciones de escolta de convoyes en la vía pública, traslado de presos de establecimientos penitenciarios de disciplina militar, protección de autoridades y labores de control de tráfico (artículos 14 y 30 del Real Decreto 194/2010), e, incluso, en situaciones excepcionales, tienen la obligación de proteger intereses privados ${ }^{52}$ e intervenir en caso de delito flagrante no estaría de más, puntualizar la forma y grado en que se deben realizar estas actividades complementarias, sobre todo la posibilidad de uso de medios coercitivos como la fuerza física, defensas de goma o utilización de esposas y pautas para la realización de detenciones ${ }^{53}$. No sería tampoco cuestión baladí, especificar normativamente la necesidad de que los miembros de este tipo de unidades especiales realizaran periódicamente cursos de actualización en materia de derechos fundamentales.

\section{USO DE LA FUERZA: ATAQUE, ABORDAJE Y REGISTRO DE LA NAVE}

\section{A) Introducción}

Las posibilidades y modo de uso de la fuerza en el mar es hoy principalmente objeto de estudio del Derecho Internacional de los Conflictos Armados. Hay unas reglas clásicas consuetudinarias que rigen la guerra marítima, fundamentalmente, respeto a las normas de Derecho Internacional Humanitario, reconocimiento de la legítima defensa bajo sujeción a los principios de necesidad y proporcionalidad del ataque, marco de acción en zonas de guerra u

\footnotetext{
${ }^{52}$ Véase así FISCHER-LESCANO, A. y KRECK, L., «Piraterie und Menschenrechte. Rechtsfragen der Bekämpfung der Piraterie im Rahmen der europäischen Operation Atalanta», en Diskussionspapier:Zentrun für Europäische Rechtspolitik, Universidad de Bremen, n. ${ }^{\circ} 3,2009$, p. 33, para quien «la piratería es un delito privado qua definitionem», cuya persecución cae dentro de las funciones típicas de la policía.

${ }^{53}$ En este sentido, como modelo, cabe destacar lo que señala la Sección $3^{\text {a }}$ de la Ley alemana para el uso de la coacción directa y el ejercicio de medidas especiales por soldados de la Bundeswehr (Gesetz über die Anwendung unmittelbaren Zwanges und die Ausübung besonderer Befugnisse durch Soldaten der Bundeswehr [UZwGBw]) que dice lo siguiente: «10. 1.-La coacción directa es la actuación sobre personas o cosas a través de la fuerza física, ciertos medios y a través de las armas. 2.-La fuerza física es toda actuación física directa a personas o cosas. 3.-Medios de fuerza física son, particularmente, los grilletes, las barreras y las propias patrullas. 4.- Armas son aquellas autorizadas oficialmente, armas blancas, armas de fuego, gases irritantes y medios explosivos. §11. El fin de la coacción directa es la disuasión, salvo cuando la situación no permita otra opción. §12.1.-Con la aplicación de medidas de coacción directa se adoptaran aquellas medidas entre las posibles que sean más apropiadas para perjudicar lo menos posible al individuo y al colectivo. 2.- Una medida de coacción directa no puede ser llevada a cabo cuando los daños previstos a través de su aplicación no estén en proporción con el hecho realizado. La medida solamente puede llevarse a cabo en tanto en cuanto sus fines lo requieren».
} 
operaciones y en aguas de Estados neutrales, posibilidades de captura de naves mercantes de los países beligerantes y métodos o medios de guerra en el mar (mísiles, torpedos, minas, margen de bloqueo, etc.) ${ }^{54}$. Pero la situación de conflagración típica entre Estados no agota el espectro de situaciones en las que un país puede verse empujado a hacer uso de la fuerza en el mar. El ejercicio del recurso de la fuerza, por ejemplo, cabe también con el propósito de salvar las vidas de las víctimas de un secuestro ${ }^{55}$ realizado por terroristas o $-\mathrm{y}$ esto es lo que ahora nos interesa- por piratas (artículo 105 de la Convención de las Naciones Unidas sobre el Derecho del Mar).

La problemática de la piratería en el Golfo de Adén y en el Índico sugiere, sin embargo, reglas de actuación específicas. Más aún ante la posibilidad de que los barcos integrantes de la Operación Atalanta puedan neutralizar - presumiblemente también hundir- «buques nodriza» desde los que operan los piratas en aguas del Índico ${ }^{56}$. Empero, la misión de la UE en las costas de Somalia tiene más un carácter policial que netamente militar ${ }^{57}$ y requiere, por tanto, unas líneas de acción, llámense éstas Reglas de Enfrentamiento (ROE) -es decir, determinación de las «circunstancias, condiciones, grado y manera» bajo las cuales el Comandante de un buque participante en el despliegue puede hacer uso de la fuerza ${ }^{58}$, que busquen también el mayor nivel de validez y garantía posible de los derechos fundamentales constitucionales en juego. En este sentido, creemos que ni la calificación de Somalia como «Estado fallido», ni, en su caso, el hecho de que el pirata pueda ser considerado sujeto al marco del Derecho de la Guerra ${ }^{59}$, debe suponer una habilitación en exceso del recurso de la fuerza extraterritorial. Tampoco la autorización del Gobierno de transición de Somalia a la persecución del delito de piratería realizado por sus

${ }^{54}$ Sobre ello, RODRÍGUEZ-VILLASANTE Y PRIETO, J. L., «Medios y métodos de combate naval y Derecho de los conflictos armados en la mar», en Revista de Derecho militar, n. ${ }^{\circ}$ 61, Ministerio de Defensa, Madrid, 1993.

${ }^{55}$ ABAD CASTELOS, M., La toma de rehenes como manifestación del terrorismo y el Derecho internacional, Ministerio del Interior, 1997, p. 212.

${ }^{56}$ La reunión de Ministros de Defensa de la UE, de 24 de febrero de 2010, amplia el margen de la misión, previendo, por parte de las fuerzas de la UE, el control de puertos y bases desde los que operan los piratas y la neutralización (abordaje y registro) de buques piratas. Sobre ello, EXPÓSITO, J. L., «Palma de Mallorca: La cita del consenso. Los Ministros de Defensa de la Unión Europea impulsan la Política Común de Seguridad y Defensa», en Revista Española de Defensa, febrero 2010, pp. 26-29.

${ }^{57}$ MIDDLETON, R., «Pirates and How to Deal With Them», en Chatham House. Briefing Papers, Londres, 2009. Este documento está disponible en red en http://www.chathamhouse.org.uk.

${ }^{58}$ Así, el documento de la Armada española, D-CP-07, Manual de Derecho Marítimo para Comandantes de Buques y Estados Mayores (apartado 0541), de 2005.

${ }^{59}$ Así, MACKINLAY, A., «La lucha contra la piratería en aguas del Oceáno Índico: la necesidad de una aproximación integral», en Real Instituto el Cano, Documento de trabajo 19/2010. Este documento está disponible en red en http://www.realinstitutoelcano.org. 
nacionales, de forma acorde al Derecho Internacional (Resolución 8016, de 2 de junio de 2008, del Consejo de Seguridad de la ONU) y al Derecho interno (artículo 561 de la Ley de Enjuiciamiento Criminal), supone una habilitación en exceso o en sentido amplio del uso de la fuerza ${ }^{60}$. Por lo tanto, y dado que en realidad la UE no está en guerra con Somalia ${ }^{61}$, pero la operación tiene un cariz militar-policial y es llevado a cabo por contingentes de las FF.AA ${ }^{62}$, es conveniente partir de una determinación de los límites de actuación en dos vertientes. Los diferentes artículos aplicables de Derecho Internacional deben, desde nuestra perspectiva, de ser completados con los preceptos relativos a derechos fundamentales de la Constitución. Hay que recordar aquí que los poderes públicos españoles no están menos sujetos a la Constitución y al resto del ordenamiento jurídico «cuando actúan en las relaciones internacionales» (STC 21/1997). Por tanto, el Derecho interno y la hermenéutica del Tribunal Constitucional y, en su caso, del Tribunal Supremo en materia de derechos constitucionales conforma también una fuente adicional para la determinación de las pautas de actuación en este tipo de situación híbrida militar-policial.

\section{B) Límites genéricos: principio de necesidad y proporcionalidad en el uso de la fuerza}

Ha sido el Tribunal Supremo, en nuestro ordenamiento jurídico, quien ha perfilado los criterios que rigen la proporcionalidad en el uso de la fuerza. La famosa sentencia de 18 de enero de 1982 dio expresión de forma concisa de cuáles son los medios que pueden utilizar las fuerzas de seguridad y según qué casos. En el particular que nos ocupa, el Tribunal Supremo, entiende que en el caso de los miembros de los cuerpos de seguridad -extrapolable perfectamente a la actuación de los soldados de Infantería de Marina (en particular del

${ }^{60}$ Sobre los límites en orden a una hipotética captura extraterritorial, véase ABAD CASTELOS, M., La toma de rehenes..., cit., pp. 214-217 y 234 y 235.

${ }^{61}$ Véase así, por ejemplo, FISCHER-LESCANO A. y KRECK, L., «Piraterie und Menschenrechte...», cit., p. 34, quienes dicen, de forma muy significativa, que «una "guerra contra los piratas" es -en tanto bajo la idea de guerra se comprende el empleo de la fuerza entre Estados, no una fórmula meramente política de decir ciertos asertos como "guerra a la droga"una contradicción preformativa». La nota a pie nos remite también a OSHANA, M., «Krieg gegen Piraten», en Blätter für deutsche und internationale Politik 12/2008, pp. 20 y ss.

${ }^{62}$ Véase, en este sentido, la STS de 7 de marzo de 2005 cuando dice que el «contexto bélico no puede reducirse al de la guerra como estado declarado formalmente en contra de un Estado, sino que ha de incluir, además, las formas en las que actualmente se manifiesta. De ahí que deba utilizarse un concepto amplio de la misma que abarque todas las formas de conflicto armado en las que intervengan tropas españolas, contando entre ellas las operaciones internacionales de mantenimiento de la paz o de apoyo a los procesos de paz, así como las que tienen un carácter humanitario y se desarrollan en escenarios en la que la situación existente pueda requerir el uso de la fuerza militar». 
Oficial al mando), en su calidad de agentes de la autoridad-, «por su preparación específica y por estar dotados de armas de fuego capaces de producir graves e irreversibles daños en la vida humana, les es exigible que su actuación venga precedida de una apreciación serena de las circunstancias que concurren en las situaciones con que se enfrentan y empleen sólo sus armas de fuego en aquellos casos en que dichas circunstancias hagan racionalmente presumir una situación de peligro o riesgo real para ellos o terceras personas, únicamente superable mediante esa utilización, y lo hagan en forma adecuada para evitar consecuencias irreparables que no vengan justificadas por la gravedad del contexto de hecho, pues en otro caso su acción resultará desproporcionada ${ }^{63}$. Este deber de proporcionalidad se traduce así, sobre todo, en una obligación, por parte de la fuerza armada, con carácter previo, de avisar de su presencia y «no sobrepasar el límite de lo racionalmente preciso para neutralizar el comportamiento violento de los sujetos» ${ }^{64}$. En este sentido, cabe recordar aquí el clásico grito ¡Alto a la Guardia Civil! con un énfasis intimidatorio para conminar al delincuente a entregarse ${ }^{65}$, o cuando el centinela antes podía decir ¡Alto al centinela! o ¡Ah del bote! o incluso ¡Alto o disparo! (artículo 558 de las Reales Ordenanzas de la Armada). Y esta es la pauta que se sigue previamente al abordaje de un buque o al ataque a una embarcación, realizando advertencias previas a través de megáfono, disparos de fogueo o al aire y cuando, caso de que estas medidas de aviso no surtan efecto y para evitar la fuga del sospechoso, se realizan también disparos a la proa del buque ${ }^{66}$ o al motor fueraborda si se trata de una lancha motora. Por cierto, este es precisamente el modus operandi que se siguió tras la liberación del atunero Alakrana el 18 de noviembre de $2009^{67}$. En este caso, el helicóptero Sikorsky SH-60 disparó unas ráfagas a la proa del bote y, en tanto los piratas no dete-

${ }^{63}$ Véase también, en similar sentido, por ejemplo, STARCK, C., «La dignidad del hombre como garantía constitucional», en FERNÁNDEZ SEGADO, F., (coord..), Dignidad de la persona, derechos fundamentales, justicia constitucional, Dykinson, Madrid, 2009, p. 284, traducción del alemán de Alberto Oehling de los Reyes, para quien, «la utilización de armas de fuego solamente puede tener justificación cuando ante un ataque no hay posibilidad de escape. Algunas leyes policiales alemanas contienen la previsión de que sólo es admisible un disparo, que con toda probabilidad puede tener un resultado mortal (por ejemplo al haber apuntado al corazón o la frente), cuando éste es el único medio para defenderse ante un peligro de vida presente o un peligro presente que pueda provocar una lesión muy grave de la integridad corporal».

${ }^{64}$ STC $126 / 2007$, de 21 de mayo, FJ. ${ }^{\circ} 5$.

${ }^{65}$ MANZANO SOUSA, M., «Estudio de un caso en el entorno penal: "Muerte en la gasolinera", un error penal invencible », en Revista Catalana de Seguridad Pública, 2004, n. ${ }^{\circ}$ 14, p. 95 .

${ }^{66}$ FERNÁNDEZ-FLORES Y DE FUNES, J. L., El Derecho de los Conflictos armados. De Iure Belli, Ministerio de Defensa, Madrid, 2001, pp. 548 y 549.

${ }^{67}$ Diario de Sesiones del Congreso de los Diputados, n. ${ }^{\circ} 126$, de 25 de noviembre de 2009, p. 12. 
nían la lancha, se trató de disparar al motor de la barca con intención de hacer parar la embarcación sin causar ninguna pérdida humana y evitar la recaptura del buque ${ }^{68}$.

\section{C) Legítima defensa y ataque}

El Comandante al mando de un buque de la Armada puede, sin necesidad de autorización inmediata del juez, en cuanto «responsable de la misión y de la seguridad del buque y la dotación» (artículo 83 de las Reales Ordenanzas de la Armada), repeler por la fuerza cualquier ataque dirigido por sorpresa contra el buque o personal de a bordo. Hay que recordar que se han dado casos de ataques a buques de guerra por parte de embarcaciones piratas, presumiblemente por error (caso del buque de aprovisionamiento francés La Somme, del USS Nicholas, del USS Ashland ${ }^{69}$ y el Spessart de la Marina alemana ${ }^{70}$ ). En el caso hipotético de que un barco de guerra español se vea en esta tesitura, podemos encontrar una justificación legal del uso de la fuerza en el Código Penal. El artículo 20.4 de este texto establece la posibilidad de defensa propia en caso de agresión ilegítima, falta de provocación suficiente del defensor, bajo proporcionalidad de los medios para repeler el ataque. Igualmente el artículo 20.7 de ese texto reconoce la eximente de legítima defensa a aquél que obre en cumplimiento del deber, oficio o cargo. En este sentido, el Tribunal Supremo, ha precisado cuales son los parámetros que en estos casos pueden justificar el uso de la fuerza: a) que los agentes actúen en el desempeño de sus funciones propias del cargo; $b$ ) que el recurso a la fuerza haya sido racionalmente necesario para la tutela de los intereses públicos o privados cuya protección les viene legalmente encomendada; c) que la fuerza utilizada sea proporcionada, actuando sin extralimitación; d) que concurra un cierto grado de resistencia o de actitud peligrosa por parte del sujeto pasivo que justifique que recaiga sobre él el acto de fuerza ${ }^{71}$. En esta misma línea, también

${ }^{68}$ La misma línea de actuación se siguió con motivo de la operación de detención de los dos piratas que, en los inicios del secuestro del Alakrana, abandonaron el barco en un esquife, el 3 de octubre de 2009. En este caso, no obstante, alguno de los disparos de intimidación desde el helicóptero se desvió e hirió levemente a uno de los presuntos delincuentes. En tanto el tirador de elite disparó bajo orden de un superior (el centro de mando operativo había ordenado la detención de la embarcación [véase el Diario de Sesiones del Congreso de los Diputados, n. ${ }^{\circ} 126$, de 25 de noviembre de 2009, p. 33]) y teniendo en cuenta la dificultad de disparar desde un helicóptero en movimiento contra un blanco a gran velocidad, no parece haber en este caso, por parte del infante de marina que realizó los disparos, infracción alguna.

${ }^{69}$ Los días 7 de octubre de 2009, 1 y 10 de abril de 2010, respectivamente.

${ }^{70}$ Sobre ello, POOLE QUINTANA, F., «Contra los piratas en el Golfo de Adén», en Revista General de Marina, Ministerio de Defensa, Madrid, Vol. 256, Junio, 2009, pp. 829-830.

${ }^{71}$ Entre otras, SSTS de 30 de septiembre de 2009, de 20 de mayo de 2008, de 9 de octubre de 2007, de 30 de septiembre de 2002, de 31 de octubre de 2000, de 24 de enero de 1994 , de 25 de marzo de 1992. 
el artículo 2.2 del Convenio Europeo de Derechos Humanos ha reconocido la posibilidad de uso de la fuerza cuando su utilización sea absolutamente necesaria, en caso de agresión ilegítima, riesgo de fuga de un preso o detenido legalmente y represión, de acuerdo con la ley, de una revuelta o insurrección. La jurisprudencia del Tribunal Europeo de Derechos Humanos, de hecho, ha reconocido, incluso, aunque de forma cauta, la posibilidad de defensa de miembros de agentes de seguridad con resultado de muerte siempre que la agresión se haya percibido como «un riesgo real e inminente para la vida del defensor o la de sus compañeros» ${ }^{72}$. No obstante, en este caso, la acción debe de estar además precedida, a efectos de su admisibilidad, de una atención reforzada de los sistemas de prevención de riesgos o ataques fortuitos ${ }^{73}$. Lo que significa que para el reconocimiento de la eximente de legítima defensa, adicionalmente, se requiere de un seguimiento previo y escrupuloso de un "protocolo de análisis de riesgos de la operación de las fuerzas de seguridad» ${ }^{74}$. Bajo estas condiciones, la decisión del Comandante de la Nave de uso de la fuerza y la defensa de los miembros de la dotación, para evitar daños personales y en el buque, resulta, por tanto, en principio, inane ${ }^{75}$.

El Comandante al mando del buque de guerra puede también, por otra parte, hacer uso, de forma premeditada y ordenada, de la fuerza para evitar cualquier tipo de ataque dirigido contra los barcos mercantes que naveguen por la zona objeto de la misión y para evitar la fuga de toda embarcación que presuntamente haya cometido un acto de piratería. La legitimación del uso de la fuerza en este caso se concreta, por un lado, en los artículos 105 y 107 de la Convención de las Naciones Unidas sobre el Derecho del Mar, que habilitan sine die a cualquier buque de guerra de un Estado a apresar un barco pirata; por otro, en la propia Acción Común 2008/851/PESC, que especifica que las fuerzas desplegadas en la Operación Atalanta «tomarán las medidas necesarias, incluido el uso de la fuerza para poner fin a los actos de piratería»

${ }^{72}$ STEDH, de 25 de agosto de 2009, Caso Giulliani y Gaggio v. Italia.

${ }^{73}$ STEDH, de 13 de marzo de 2007, Caso Huohvanainen v. Finlandia.

${ }^{74}$ REY MARTÍNEZ, F., «La protección jurídica de la vida: Un derecho en transformación y expansión», en GARCÍA ROCA, J. y SANTOLAYA MACHETTI, P. (Coords.), La Europa de los derechos. El Convenio Europeo de los Derechos Humanos, Centro de Estudios Políticos y Constitucionales, Madrid, 2005, p. 76.

${ }^{75}$ Véase, por ejemplo, el Auto de la Audiencia Nacional de 5 de marzo de 2010, por la que el Juez Santiago Pedraz archivó la denuncia que había interpuesto uno de los secuestradores del Alakrana contra la Armada, por haber sido herido de bala durante su detención el día 3 de octubre de 2009. Para el Juez queda acreditado que los miembros del operativo de asalto de la fragata Canarias habían actuado «en legítima defensa», ya que solamente procedieron a realizar dispararos de intimidación tras la renuencia de los somalíes a obedecer la petición del jefe del equipo de asalto que detuvieran el esquife, y después de creer, toda vez que «una de las personas se levantó brusca y repentinamente iniciando un movimiento sospechoso con la mano», que éste «iba a sacar un arma». 
(artículo 2.d). No obstante lo anterior, se entiende que, en este caso, el Comandante al mando, en cuanto tenga conocimiento de un ataque pirata contra un buque civil, debe comunicarlo al Comandante del Mando de Operaciones del EMAD y al Comandante de la Fuerza Naval de Atalanta ${ }^{76}$.

\section{D) Abordaje y registro de la nave}

En principio el abordaje y registro de un buque requiere de la previa autorización del capitán de la nave o del Estado cuyo pabellón enarbola el buque (artículo 561 de la Ley de Enjuiciamiento Criminal). Como ya hemos dicho, la autorización por parte del Gobierno de transición de Somalia por vía de la Resolución 1816, de 2 de junio de 2008, del Consejo de Seguridad de la ONU supone una dispensa de la necesidad de solicitar permiso en el caso de abordaje y registro de un buque de este país. Esta habilitación faculta el abordaje de los denominados «buques nodriza» (barcos de transporte de mercancías de autonomía importante capaces de distanciarse hasta 900 y 1000 millas de la costa ${ }^{77}$, de una tripulación de entre 30 y 60 hombres y que disponen de lanchas que se arrían al agua para acercarse a otros objetivos y atacarlos por sor$\left.\operatorname{presa}^{78}\right)$, como también de lanchas motoras, esquifes u otro tipo de embarcaciones de pequeña eslora. De otra parte, caso de que el abordaje se produzca sobre una nave de otro país, la necesidad de impetrar autorización difiere de la categoría de la embarcación. Hemos de tener en cuenta que nuestra normativa se refiere expresamente a casos de abordaje y registro de «buques mercantes», por lo que en el supuesto de otro tipo de barcos como, por ejemplo, un barco velero de recreo o un yate no parece estrictamente necesario recabar autorización previa ${ }^{79}$. Por otro lado, hay que tener también en cuenta que la imperatividad de solicitud de autorización ante el mero abordaje y registro es una obligación relativa en el caso de naves sospechosas de cometer el delito de piratería ${ }^{80}$, ya que -a pesar de lo que establece el Derecho interno- el artículo 22 del Convenio de Ginebra sobre Alta Mar de 1958 ha-

${ }^{76}$ «Contestación del Gobierno en el Congreso a la Diputada Beatriz Rodríguez-Salmones Cabeza». Véase en Boletín Oficial de las Cortes Generales, Congreso de los Diputados, n. ${ }^{\circ}$ 288, 11 de noviembre de 2009, pp. 228-229.

${ }^{77}$ DE ANDRÉS, J. C., «Terrorismo y piratería marítima. Operación Atalanta», Conferencia pronunciada con motivo del Curso de experto en Seguridad y Defensa: Gestión de crisis y comunicación, en la Universidad Alfonso X el Sabio, el día 12 de febrero de 2010.

${ }^{78}$ SALVATIERRA, M., «Piratas globalizados: viejas prácticas, nuevos desafíos», en Política Exterior, n. ${ }^{\circ}$ 128, Marzo-Abril, Centro de Estudios de Política Exterior, Madrid, 2009, p. 159.

${ }^{79}$ STS de 29 de mayo de 2001.

${ }^{80}$ También, por otro lado, este requisito de solicitud al Estado cuyo pabellón enarbola el buque, ha sido relativizado igualmente para otro tipo de delitos como, por ejemplo, en caso de tráfico de estupefacientes. Véase, por ejemplo, STS de 25 de noviembre de 2003. 
bilita directamente a cualquier buque de guerra cuando tenga fundadas sospechas de que un barco es pirata a proceder a su visita, realizar la pertinente investigación y en el caso de que se compruebe este extremo realizar la detención de su tripulación y el apresamiento del buque ${ }^{81}$.

La garantía de «interdicción de la actividad de los poderes públicos (artículo 9.3 de la Constitución), presupone el control e intervención del juez de la actuación de abordaje y registro del buque. Toda vez que es difícil, aunque sería la solución ideal, embarcar un juez - «juez de a bordo» que dijera Lanza $^{82}$ - para la práctica de este tipo de diligencias, debe haber al menos una comunicación, más o menos fluida, con el órgano judicial para que este se encuentre informado en todo momento de la situación ${ }^{83}$. El presupuesto habilitante para el abordaje y detención de la tripulación tiene lugar por medio de un acto individual en forma de Auto motivado por el juez ${ }^{84}$, que, en principio, prevé además la inspección y registro de la nave. La Sentencia del Tribunal Supremo 55/2007, de 23 de enero, permite, no obstante, cierta inconcreción respecto al día y la hora en que el Instructor autoriza el abordaje del buque. Con ello se prevén posibles incidencias o retrasos en su práctica debido a las «vicisitudes» propias de la navegación del barco ${ }^{85}$. Ahora bien, tampoco la ausencia de autorización judicial inmediata o nulidad del mandamiento judicial que acuerda al abordaje o las actuaciones de los infantes de marina realizadas para abordar el barco y comprobar si éste se dedica a la piratería supone una invalidez per se de la práctica de la interceptación y

${ }^{81}$ CERVERA PERY, J., El Derecho del mar. Evolución, contenido, perspectivas (De las Bulas Papales al Convenio de Jamaica), Editorial Naval, Madrid, 1992, p. 121.

${ }^{82}$ LANZA, S., (pseudónimo de Juan Bautista AMOROS Y VÁZQUEZ DE FIGUEROA), Desde la quilla hasta el tope, Imprenta de Fernando Cao, Madrid, 1891, p. 94.

${ }^{83}$ «En caso de que se produzca un ataque pirata contra buque de pabellón no español, en el que participan fuerzas españolas, el Comandante del buque comunicará los hechos al Comandante del Mando del Estado Mayor de la Defensa y al Comandante de la Fuerza Naval de Atalanta (...). El Comandante del Mando del Estado Mayor de la Defensa lo notificará al Juzgado de Guardia de la Audiencia Nacional que decidirá sobre su competencia». Por otro lado, en el caso de que el ataque se produzca sobre un buque de pabellón español el Comandante del buque de guerra español «deberá comunicarlo de forma inmediata al Comandante del Mando del Estado Mayor de la Defensa; que en cumplimiento de la legislación nacional lo pondrá en conocimiento del Juzgado Central de Instrucción de guardia la Audiencia Nacional, cumplimentando las órdenes que emanen de su auto y comunicando las decisiones que toma al Cuartel General de la Operación Atalanta en Northwood». Véase en Boletín Oficial de las Cortes Generales, Congreso de los Diputados, n. ${ }^{\circ} 288,11$ de noviembre de 2009, p. 228.

${ }^{84}$ También, en algún caso, se ha aceptado la autorización concedida por el juez de guardia y solicitada telefónicamente por el fiscal, validada después por escrito en puerto (STS de 27 de octubre de 2005).

${ }^{85}$ OEHLING DE LOS REYES, A., «Los derechos del detenido en caso de apresamiento de buque en alta mar», Revista General de Marina, Ministerio de Defensa, Madrid, Vol. 256, Marzo, 2009, p. 254. 
registro. En primer lugar, porque, como hemos dicho, la interceptación del buque sospechoso encuentra su apoyo en las disposiciones de Derecho Internacional citadas, incorporadas al ordenamiento jurídico español por su ratificación. Y en segundo término hay que advertir que la situación de flagrancia exime también de la observancia inmediata de impetrar auxilio judicial previo al abordaje e inspección de la nave ${ }^{86}$. En definitiva, la garantía de intervención judicial inmediata de la interceptación y registro del buque en alta mar, es relativa, por cuanto, además, que duda cabe que si la actuación de los efectivos de la Armada tiene que ser pospuesta en casos de urgencia hasta la recepción del mandamiento judicial y aguardar la autorización de entrada y registro, es muy posible que la espera durante un lapso de tiempo desmesurado podría llevar en muchos casos a la más absoluta esterilidad de la operatividad de la contribución española a la seguridad en la zona ${ }^{87}$.

\section{a) Procedimiento de ejercicio}

La inspección del barco requiere de su previa interceptación. El Convenio de Ginebra sobre Alta Mar de 1958 y el Convenio de las Naciones Unidas sobre el Derecho del Mar de 1982 atribuyen competencia para proceder a la retención de un buque pirata sólo a buques de guerra o de seguridad del Estado (artículos 21 y 107, respectivamente). Esto no significa que un buque comercial no pueda defenderse ${ }^{88}$-como reconoce el Real Decreto 1628/2009, de 30 de octubre, por el que se modifica el Reglamento de Seguridad Privada y el Reglamento de Armas ${ }^{89}$-, pero sí excluye a éstos la posibilidad de persecución, detención y captura de barcos sospechosos de haber realizado el delito de piratería. En este contexto, el Convenio de Ginebra y el Convenio de las Naciones Unidas, en sus artículos 22.2 y 110.2, prevén que la nave de guerra podrá enviar al buque objeto de investigación un bote, al mando de un Oficial, para proceder a la visita e inspección de la embarcación. Importa además dejar constancia que previo al envío de la lancha con miembros de la tripulación es necesario, tras requerir al mando del buque contrario que proceda a detener la nave, asegurar el objetivo -incluso a través de la utilización de la fuerza- para evitar todo tipo de resistencia armada. Por razones de lógica y seguridad hay que entender que, en caso de que fuera necesario, cabe desviar a la nave pirata a una zona o puerto seguro para ejercer el derecho de visita y registro. En este sentido, hay que decir también que, en el supuesto de resis-

${ }^{86}$ Véase la STS de 1 de marzo de 1996.

${ }^{87}$ Compárese, STS de 9 de octubre de 1998.

${ }^{88}$ RODRÍGUEZ NÚÑEZ, A., «El delito de piratería», en Anuario de Derecho penal y Ciencias penales, Vol. 50, Ministerio de Justicia-BOE, Madrid, 1997, p. 224.

${ }^{89}$ Véase también la Recomendación de la Comisión, de 11 de marzo de 2010, relativa a las medidas de autoprotección y de prevención de los actos de piratería marítima y los ataques a mano armada perpetrados contra buques. $D O$ n. ${ }^{\circ}$ L 67, de 17 de marzo de 2010. 
tencia o huida, existen razones suficientes para su abordaje, captura ${ }^{90} \mathrm{y}$, en su caso, su hundimiento o embargo ${ }^{91}$.

\section{b) Neutralización de la tripulación contraria}

El abordaje implica reducir y controlar la tripulación de la nave pirata. Poco dice el Real Decreto 194/2010, de 26 de febrero, sobre cómo o qué medios pueden utilizarse para neutralizar a las personas que ofrezcan resistencia a la retención. Realizando una interpretación extensiva de la Instrucción 12/2007 de la Secretaría de Estado de Seguridad sobre comportamientos exigidos a los miembros de las Fuerzas y Cuerpos de Seguridad del Estado, en cuanto al carácter de agente de la autoridad de la Policía Naval en ejercicio de sus funciones, cabe también en este caso empleo de «coacción directa», si bien buscando siempre la menor lesividad del detenido (Instrucción $1^{\mathrm{a}}$.4). En este sentido, el agente deberá seleccionar para el ataque partes no vitales y graduar la contundencia y el modo de ejecución de los actos violentos, dependiendo de la agresividad del sujeto; una vez ésta cesa debe cesar la coacción. El agente, además, podrá hacer uso de armas de fuego, pero solamente con efectos disuasorios o cuando exista riesgo racionalmente grave para su vida, su integridad física o la de terceras personas. En todo caso, tanto el arma de fuego reglamentaria como el uso de otro tipo de defensas (porra de goma o esposas), deben ser proporcional a la resistencia ofrecida por el sujeto (Instrucción $7^{\mathrm{a}}$ ).

\section{c) Inspección de cámaras «aptas para la vida íntima» del buque}

Desde el momento en que, por un lado, se reconoce por la Constitución la inviolabilidad del domicilio como derecho fundamental (artículo 18.2), y, por otro lado, reiterada jurisprudencia del Tribunal Supremo ha entendido también un camarote de un barco -en cuanto «lugar separado donde uno de los tripulantes o viajeros se independiza de los demás (...), para desarrollar su privacidad»- como domicilio ${ }^{92}$, se puede considerar que la única forma de proceder a su registro es mediando consentimiento del titular o resolución judicial, salvo caso de delito in fraganti o caso de fuerza mayor ${ }^{93}$. La razón es muy sencilla. Como se sabe, el Tribunal Constitucional concibe el domicilio como medio para la protección de la intimidad personal, definiendo éste más 549.

${ }^{90}$ FERNÁNDEZ-FLORES Y DE FUNES, J. L., El Derecho de los Conflictos..., cit., p.

${ }^{91}$ Artículo 2.e de la Acción común 2008/851/PESC del Consejo, de 10 de noviembre del 2008.

${ }^{92}$ Entre otras, SSTS de 10 de abril de 2002, de 12 de julio de 2004 y de 17 de septiembre de 2009.

${ }^{93}$ Véase, por ejemplo, la STS de 3 de marzo de 2010. 
en términos de espacio donde el individuo «ejerce su libertad más íntima» (STC 22/1984), «ámbito propio y reservado frente al conocimiento de los demás» (STC 231/1988) o «espacio apto para la vida privada» (STC 10/2002). En estas circunstancias, la necesidad de impetrar auxilio judicial para la práctica de esta diligencia depende también de la categoría y función de la embarcación ${ }^{94}$. De esta forma, en embarcaciones de pequeña eslora, que carecen de zonas interiores para evitar la intromisión ajena, se entiende que no se precisa cobertura judicial en orden a su registro ${ }^{95}$. La misma regla parece aplicable en orden a aquellas otras dependencias de un barco que no sean camarotes -por ejemplo, la bodega o la zona de máquinas- o no sirvan para la realización de la vida privada ${ }^{96}$. Es, por tanto, en barcos de cierto empaque, con dependencias destinadas al ejercicio de la vida íntima, donde sería necesaria en principio, la autorización del órgano judicial ${ }^{97}$.

El derecho fundamental a la inviolabilidad del domicilio del artículo 18.2 de la Constitución, no obstante, no es un derecho absoluto y, de la misma manera que en el caso de abordaje, caben ciertas excepciones a la regla general. En este sentido, al margen de los límites establecidos por la propia Constitución (consentimiento del titular, resolución judicial y caso de delito flagrante) y la previsión del artículo 21.3 de la Ley Orgánica 1/1992, de 21 de febrero, de Protección de Seguridad Ciudadana (caso de fuerza mayor, para evitar daños inminentes y graves en personas o cosas), encontramos la habilitación genérica del artículo 553 de la Ley de Enjuiciamiento Criminal. Por un lado, este artículo prevé la posibilidad de que los miembros de los institu-

${ }^{94}$ En este sentido, véase, por ejemplo, ALONSO DE ANTONIO, Á. L., El derecho a la inviolabilidad domiciliaria en la Constitución española de 1978, Colex, Madrid, 1993, pp. 93 y 94, quien distingue también el caso de barcos de pasajeros -pensemos en un ferry sin camarotes para unir distancias cortas- que, como un autobús urbano o como un avión sería un mero medio de transporte, en cuyo caso, su registro e inspección, no gozaría del mismo nivel de protección.

${ }^{95}$ Esta previsión puede extenderse a los barcos pesqueros, en tanto «dadas las características del barco y su uso exclusivo para la pesca, no podría tratarse en forma alguna de lo que el precepto constitucional considera como domicilio, siendo equiparable su naturaleza a la de un automóvil que, según reiterada jurisprudencia, no requiere mandamiento judicial para su registro, por no suponer un reducto de la intimidad personal o familiar» (SSTS de 16 de diciembre de 1999 y de 24 de febrero de 2010).

96 «Es dificultoso extender el concepto de domicilio en todo caso a otras zonas del buque, como puede ocurrir con la cubierta, utilizada en las maniobras náuticas o como lugar de esparcimiento, que no pueden entenderse aptas, con carácter general, para la vida privada». SSTS de 10 de abril de 2002, de 12 de julio de 2004, de 17 de septiembre de 2009 y de 24 de febrero de 2010.

${ }^{97}$ Además, los camarotes o espacios destinados a habitación de la tripulación tienen que ser utilizados efectivamente para ese fin, dado que en caso de utilización de tales dependencias para otros usos, por ejemplo, para depósito de mercancías, decae igualmente la protección del artículo 18.2 de la Constitución. Véanse así, por ejemplo, SSTS de 9 de octubre de 1998, de 16 de diciembre de 1999, de 20 de febrero de 2006 y de 17 de septiembre de 2009. 
tos armados, por propia iniciativa, puedan proceder a la detención de personas cuando sean sorprendidas en flagrante delito o cuando un delincuente, inmediatamente perseguido por los agentes de la autoridad, se oculte o refugie en alguna casa. Y, por otro lado, permite incluso que puedan proceder al registro de aquel lugar que, con ocasión de dicha detención, consideren conveniente a efectos de aprehender todo tipo de pruebas o efectos que pudieran guardar relación con el delito perseguido ${ }^{98}$. Asimismo, como ya se ha dicho, las previsiones del artículo 22 del Convenio de Ginebra sobre Alta Mar y del artículo 110.2 del Convenio de las Naciones Unidas sobre el Derecho del Mar de 1982, también habilitan al barco de guerra en caso de que haya motivo razonable para sospechar que un buque se dedica a la piratería, a requerir la detención del barco y proceder a su inspección. En cualquier caso, no obstante, interesa apuntar que esta facultad genérica requiere que el Comandante al mando de la maniobra, tras la realización de la diligencia, dé parte al Juez competente, con expresa mención de las causas que motivaron el registro, resultados obtenidos, detenciones realizadas, intervinientes y, en su caso incidentes ocurridos (artículo 553 de la Ley de Enjuiciamiento Criminal) ${ }^{99}$.

\section{d) Competencia de los miembros de la Policía Naval para la práctica de la diligencia}

Respecto a la posible competencia de la Policía Naval para la realización del registro, cabe decir que el artículo 29.2 del Real Decreto 194/2010, de 26 de febrero, por el que se aprueban las Normas sobre seguridad en las FF.AA, atribuye a sus miembros, como hemos mencionado anteriormente, el carácter de «agentes de la autoridad» en ejercicio de sus funciones. El carácter de Policía Judicial de la Policía Naval -al menos como instituto colaborador de las Fuerzas y Cuerpos de Seguridad, por ejemplo, en el sentido de los Servicios de Vigilancia Aduanera ${ }^{100}$ - podría ser deducido, por otra parte, del sen-

${ }^{98}$ En cuanto a su aplicación en caso de registro de camarote en alta mar, mediando flagrancia delictiva pero sin resolución judicial, véanse SSTS de 7 de marzo de 2007 y de 24 de febrero de 2010.

${ }^{99}$ La flagrancia se define como «aquella situación fáctica en la que el delito se percibe como evidente» (STC 341/1993). Por otra parte, los requisitos de este límite a la inviolabilidad son: la inmediatez temporal, la inmediatez personal y la necesidad urgente. Es decir, «es pues preciso que el delito se esté cometiendo en ese momento, y que, por ello, el delincuente se encuentre allí con inmediatez respecto al objeto e instrumentos del delito y que mediante la entrada la policía pueda poner término a la situación, impidiendo en todo lo posible la propagación del mal que la infracción acarrea (SSTS de 22 de febrero de 1990 y de 29 de marzo de 1990)». Cit. en LÓPEZ BARJA DE QUIROGA, J., Tratado de Derecho procesal penal, Thomson-Aranzadi, Pamplona, 2007, p. 1108.

${ }^{100}$ Sobre la calificación de los agentes de este servicio como Policía Judicial, véase el artículo 1 de la Ley Orgánica 12/1995, de 12 de diciembre, de Represión del Contrabando y ATS de 31 de julio de 1998. 
tido amplio del artículo 283 de la Ley de Enjuiciamiento Criminal que deja entender que los Jefes y Oficiales «de cualquier fuerza destinada a la persecución de malhechores» pueden actuar como Policía Judicial o como colaboradores de Jueces y Tribunales en orden a la averiguación de delitos y persecución de delincuentes. Desde esta perspectiva, en tanto el artículo 85 de la Ley Orgánica 4/1987, de 15 de julio, de Competencia y Organización de la Jurisdicción Militar, determina a la Policía Naval como un instituto dependiente de la Jurisdicción Militar parece complejo su encaje como Policía Judicial. Empero, en casos especiales, como es el caso de la Operación Atalanta, de tipo más policial que militar y bajo dependencia y supervisión de los Jueces y Tribunales competentes en materia penal, no hay óbice, desde nuestro punto de vista, de que los miembros de la Policía Naval -al menos los oficiales ${ }^{101}$ - puedan ostentar este carácter ${ }^{102}$. Esta condición de Policía Judicial a los oficiales de Infantería de Marina integrantes de la Policía Naval debería ser, no obstante, perfilada a través de una modificación de la Ley 2/1986, de 13 de marzo, de Fuerzas y Cuerpos de Seguridad.

El artículo 569 de la Ley de Enjuiciamiento Criminal, en realidad, exige que el registro se realice «siempre en presencia del Secretario Judicial». Este es, por tanto, el único funcionario que tiene verdaderamente reconocida en nuestro ordenamiento jurídico competencia de fedatario público judicial y capaz de dejar verdadera constancia de la legalidad de las actuaciones. Excepcionalmente, el artículo 451.4 de la Ley Orgánica 6/1985, de 1 de julio, del Poder Judicial permite también su sustitución, para casos de entrada y registro acordados por la Audiencia Nacional a los funcionarios del Cuerpo de Gestión Procesal-Administrativa ${ }^{103}$. En la medida, por tanto, en que se pueda proceder al embarque de un Secretario Judicial o un miembro del Cuerpo de Gestión Procesal para una operación en alta mar, podrán implementarse estos preceptos en sus estrictos términos ${ }^{104}$. Empero, desde el momento en que, en

${ }^{101}$ En este sentido, los mandos de la Policía Naval seleccionados para tales cometidos podrían también realizar el curso correspondiente al que hace referencia el artículo 32 de la Ley 2/1986, de 13 de marzo, de Fuerzas y Cuerpos de Seguridad.

${ }^{102}$ En contrario, véase, ROVIRA DEL CANTO, E., «El artículo 126 de la Constitución española y su desarrollo en el ámbito castrense», en Cuadernos de la Guardia Civil, n. ${ }^{\circ} 11$, 1990, p. 22, para quien no hay lugar a considerar a la Policía Militar como Policía Judicial en tanto sus miembros pueden seguir las directrices y ordenes dadas por sus superiores «con preferencia a las de los órganos judiciales».

${ }^{103}$ En este sentido, MORALES MUÑOZ, E., «Diligencias de investigación en el proceso penal. La diligencia de entrada y registro. Tercer presupuesto: autorización judicial. Procedimiento para su práctica. Efectos de las entradas y registros domiciliarios inconstitucionales (II)», en Boletín de Información del Ministerio de Justicia , n. ${ }^{\circ} 2037$, Ministerio de Justicia, Madrid, 2007, p. 16

${ }^{104}$ Una solución se ofrece: la activación y embarque de un Oficial o Suboficial (RV) que desempeñe estos cometidos en la vida civil. 
casos tasados, por un lado, se admite por el Derecho Internacional la obligación de los buques civiles de ceder ante la petición del mando de un barco de guerra y permitir la inspección, y, por otro lado, la mayoría de las veces en este tipo de operaciones la Armada actúa bajo el presupuesto de flagrancia, se puede entender $-\mathrm{y}$ esto es lo que nos interesa ahora-, a falta de mandato judicial inmediato, que la presencia del Secretario Judicial podría ser sustituida por la declaración de los intervinientes en el registro, por ejemplo, de los agentes de la autoridad ${ }^{105}$.

\section{e) Practica de la diligencia}

Las posibilidades de abordaje, inspección y registro son, por tanto, amplias. Empero, los artículos 545 y siguientes de la Ley de Enjuiciamiento Criminal regulan un procedimiento formal para los supuestos de registro domiciliario. Realizando una interpretación comparativa de algunos de estos preceptos cabe identificar unas pautas generales válidas para el caso de inspección de buque en alta mar. En el caso hipotético de que los servicios de la Policía Naval se vean en la vicisitud de realizar un registro, de conformidad con estos artículos, requiere de los siguientes trámites:

$1^{\circ}$ ) En el caso de disponer de mandato judicial para la realización de la diligencia, éste se debe notificar al titular -Capitán- del buque (artículo 566 de la Ley de Enjuiciamiento Criminal). En este sentido, dadas las circunstancias, la especialidad del ilícito que se investiga y el lugar en que se realiza, la situación de abordaje de una nave pirata en alta mar se diferencia en gran manera de aquel que se realiza con proximidad del barco a puerto nacional o que ha dispuesto de una investigación iniciada con tiempo de antelación. En tales supuestos quizás pueda darse la posibilidad de notificar inmediatamente al interesado el Auto que habilita la inspección y registro. Pero en el caso de alta mar y en el caso de una operación contra una embarcación pirata, la finalidad del buque de guerra es proceder lo más rápido posible y con la máxima seguridad de los miembros del operativo al abordaje de la nave. Como antes apunté, una respuesta eficaz y precisa para el cumplimiento de la misión encomendada por la Acción Común 2008/851/PESC exige cierta flexibilidad haciendo prevalecer las previsiones más amplias del Convenio de Ginebra sobre Alta Mar y del Convenio de las Naciones Unidas sobre el Derecho del Mar- en lo que al mandato judicial se refiere. Más precisamente: exigir poner en conocimiento del Juez, desde alta mar, con carácter previo a la maniobra, los indicios que prueban la conducta ilícita, y aguardar la autorización de entrada y registro, que, como es sabido, ha de ser mediante documento escrito, requeriría un lapso de tiempo desmesurado y conduciría al fracaso de la ac-

${ }^{105}$ SSTS de 23 de mayo de 1994, de 21 de noviembre de 1994 y de 14 de noviembre de 1997. 
tuación ${ }^{106}$. Lo fundamental en este tipo de operaciones es que el Juez, en cuanto sea posible, «controle y esté informado de las circunstancias e incidencias de la actuación». Los demás requisitos de forma, deben depender de las vicisitudes de la navegación en alta $\operatorname{mar}^{107}$ y de la seguridad de la operación.

$2^{\circ}$ ) No hace al caso profundizar excesivamente en el hecho de que es conveniente proceder al registro de las cámaras y dependencias del buque, si fuese posible, cosa que en alta mar es bastante improbable, con la asistencia de testigos, de un Secretario Judicial o de un miembro del Cuerpo de Gestión Procesal -su presencia, hemos dicho, podría ser sustituible por la declaración de los intervinientes en el registro, por ejemplo, de los agentes de la autoridad-, y, en su caso, de un letrado (artículo 569 de la Ley Rituaria Criminal). Lo que si importa reseñar son dos cuestiones fundamentales en orden a la interpretación de este precepto. Por un lado, que la doctrina del Tribunal Constitucional ha reconocido que la omisión de este tipo de requisitos o las incidencias que en su práctica se puedan suceder no se pueden considerar violación del derecho fundamental del artículo 18.2 de la Constitución, sino solamente lesión de obligaciones de tipo procesal y de mera legalidad ordinaria ${ }^{108}$. Y, por otro lado, que en caso de que ya se haya procedido a la detención de los sospechosos, quedando estos a disposición judicial, el registro no puede realizarse sin ofrecer al detenido la oportunidad de estar presente durante la inspección ${ }^{109}$. La ausencia del interesado que se encuentre detenido, en el momento de realizar el registro, supone la nulidad «radical e insubsanable de la prueba practicada ${ }^{110}$. De esta suerte, la falta de presencia del interesado durante la realización de la diligencia solamente se puede obviar en casos de fuerza mayor que dificulten en extremo la presencia de éste ${ }^{111} \mathrm{o}$ cuando los camarotes o habitáculos de la embarcación sean tan reducidos que físicamente no haya lugar para varias personas. En este último caso, es suficiente para la validez de la diligencia «que los interesados puedan visionar la labor general de los agentes y comprobar dónde y cómo se van hallando cualesquiera objetos vinculados con la presunta actividad delictiva, sin tener que estar presentes en cada uno de los recovecos del barco que son objeto de registro» ${ }^{112}$.

${ }^{106}$ Casi literalmente, STS de 9 de octubre de 1998.

${ }^{107}$ STS de 23 de enero de 2007.

${ }^{108}$ SSTC 133/1995, 228/1997, 239/1999 y 82/2002.

${ }^{109}$ Véase así SANZ MARQUÉS, L., «Las actuaciones de investigación e instrucción extrafronterizas», p. 1424. Trabajo disponible en Internet en la página del Centro de Estudios Jurídicos del Ministerio de Justicia, http://www.cej.justicia.es/cej/html/publicaciones_01.htm

${ }^{110}$ Véanse, entre otras, SSTS de 15 de febrero de 1995, de 24 de marzo de 1995, de 8 de octubre de 1998 y 29 de diciembre de 2000. Sobre ello, citando jurisprudencia, LÓPEZ BARJA DE QUIROGA, J., Tratado de Derecho procesal penal, cit., p. 1089.

${ }^{111}$ SSTS de 21 de mayo de 1993 y de 15 de febrero de 1997.

${ }^{112}$ STS de 23 de febrero de 2010. 
$3^{\circ}$ ) La resistencia del Capitán del barco, la tripulación o los pasajeros no impedirá la práctica de la diligencia (artículo 569 de la Ley de Enjuiciamiento Criminal), sin perjuicio de que esta actitud pueda ser considerada constitutiva del delito de «desobediencia grave a la autoridad» (artículos 550 y 551 del Código Penal). En el caso de que se llegue a producir resistencia por parte de algún sujeto a la inspección -al margen de que pueda ser reducido ${ }^{113}$-, el Oficial al mando de la operación de registro podrá apercibir al interesado del delito en que su comportamiento pueda incurrir haciéndolo constar en el parte o acta que levante con posterioridad ${ }^{114}$.

$4^{\circ}$ ) En el registro de dependencias privadas y camarotes de un buque «deben evitarse inspecciones inútiles» (artículo 552 de la Ley Rituaria). Este principio tiene particular validez en caso de ejercicio del derecho de visita e inspección rutinaria para la realización -en caso de sospecha- de las comprobaciones necesarias a las que se refiere el artículo 110.2 del Convenio de las Naciones Unidas sobre el Derecho del Mar. En estos casos, dado que cabe la posibilidad de que el registro tenga un resultado nulo y no se encuentre a bordo ninguna prueba incriminatoria, se tienen que extremar las precauciones para no perjudicar ni importunar al interesado más de lo necesario durante la retención. Esta regla es válida también para el registro de un buque tras su liberación. En este sentido, la revisión de camarotes e instancias de la tripulación y pasajeros liberados debe de realizarse respetando sus pertenencias, secretos u objetos personales que no interesen a la práctica de la diligencia. Por otro lado, obligado es recordar en relación a esta previsión, que el artículo 534.2 del Código Penal sanciona a «la autoridad o funcionario público que, con ocasión de registro de papeles, documentos o efectos de una persona, cometa cualquier vejación injusta o daño innecesario en sus bienes». Esta figura es aplicable, cuando, por ejemplo, tratándose de un registro bajo cobertura constitucional, legal o judicial, en el desarrollo de la diligencia se producen extralimitaciones o apropiaciones indebidas ${ }^{115}$.

$6^{\circ}$ ) Los miembros del comando de abordaje pueden hacer uso de cámaras de video, salvo que se viole el domicilio, la intimidad y la dignidad de la persona ${ }^{116}$. «La captación de imágenes se encuentra autorizada por la ley en el curso de una investigación criminal siempre que se limiten a la grabación de lo que ocurre en espacios públicos fuera del espacio inviolable del domicilio donde tiene lugar el ejercicio de la intimidad» ${ }^{117}$. Por tanto, la filmación

${ }^{113}$ Cfr. supra Apartado 4.D.b.

${ }^{114}$ Compárese, MORALES MUÑOZ, E., «Diligencias de investigación en el proceso...», cit, p. 22

${ }^{115}$ Sobre ello, SÁNCHEZ GARCÍA DE PAZ, I., «Delitos contra la Constitución: Delitos cometidos por los funcionarios públicos contra las garantías constitucionales», en Cuaderno del Instituto Vasco de Criminología , n. ${ }^{\circ}$ 14, San Sebastián, 2000, pp. 130 y 131.

${ }^{116}$ SSTS de 25 de noviembre de 2006 y 26 de octubre de 2000.

${ }^{117}$ STS de 13 de marzo de 2003. 
del «espacio restringido reservado para la intimidad de las personas sólo puede ser acordado en virtud de mandamiento judicial» ${ }^{118}$. Y de conformidad con ello, la utilización por los participantes de la operación -sin el oportuno placet judicial- de este tipo de medios técnicos queda limitado a la grabación de dependencias no privadas del buque (cubiertas, sala de máquinas, bodega, pañol, cocina, lavandería, etc.).

$7^{\circ}$ ) En términos del artículo 572 de la Ley de Enjuiciamiento Criminal, realizada la inspección, el Oficial encargado del operativo debe formalizar informe o acta del registro, expresando, el nombre -caso de disponer de mandamiento judicial al efecto- del Juez responsable de la intervención, del Oficial y Suboficial que hayan dirigido la inspección, nombre de los infantes de marina participantes en la operación, hora de inicio y finalización de la diligencia, incidencias o quejas, así como los resultados obtenidos. El procedimiento termina con el decomiso o incautación del material probatorio hallado, que será guardado en cajas, bolsas o sobres, sellado y firmado por el mando y el Suboficial encargado ${ }^{119}$.

\section{E) Incautación y hundimiento}

La incautación, embargo e incluso hundimiento de una embarcación o buque tiene su justificación cuando se tiene certeza de que se trata de una nave pirata ${ }^{120}$, por razones de prevención del ilícito, y para evitar la realización de ulteriores actos de piratería ${ }^{121}$. Así, por ejemplo, la fragata Victoria ha procedido a hundir un «buque nodriza» y una ballenera pirata en el Índico (días 15 y 25 de abril de 2010, respectivamente). Igualmente, es costumbre hundir los esquifes y lanchas piratas tras la detención de sus ocupantes. Podemos encontrar una base legal de esta medida en el Convenio de Ginebra sobre Alta Mar y el Convenio de las Naciones Unidas sobre el Derecho del

\footnotetext{
${ }^{118}$ Ibídem.

${ }^{119}$ En realidad, la calidad de depositarios de la fe pública judicial y de dejar constancia de la legalidad de las actuaciones queda reservada a los Secretarios Judiciales en virtud del artículo 453 de la Ley Orgánica 6/1985, de 1 de julio, del Poder Judicial. En este sentido, dada la dificultad de implementar este precepto en sus estrictos términos con ocasión de una operación en alta mar (Cfr. supra nota . $^{\circ}$ 109), esta función puede ser asumida, excepcionalmente, por el Oficial del equipo de abordaje e inspección.

${ }^{120}$ Véase así, por ejemplo, STS de 24 de octubre de 2007, cuando afirma que el comiso de la embarcación sólo procede cuando ésta haya sido utilizada para la comisión de un delito.

${ }^{121}$ Compárese, por ejemplo, GRACIA MARTÍN, L. / ALASTUEY DOBÓN C. / BOLDOBA PASAMAR, M., Las consecuencias jurídicas del delito en el nuevo Código Penal: el sistema de penas, medidas de seguridad, consecuencias accesorias y responsabilidad civil derivada del delito, Tirant lo Blanch, Valencia, 1996, pp. 447 y 448, para quien el fundamento del comiso está en la peligrosidad del uso peligroso que un sujeto puede hacer de ciertos bienes.
} 
Mar de 1982. En efecto, los artículos 19 y 105 de estos documentos prevén la posibilidad de apresar un buque pirata e incautar los bienes que se encuentren a bordo. También el artículo 2.e de la Acción Común 2008/251 PESC reconoce la facultad de los buques que forman parte de la misión Atalanta de capturar o proceder al embargo de una nave pirata. En el plano del Derecho interno hay que citar el artículo 374 del Código Penal que también permite el comiso o confiscación de una embarcación cuando haya sido empleada para cometer infracción penal o administrativa ${ }^{122}$.

No contienen, sin embargo, estos textos una normativa o unos parámetros de cómo se debe proceder al hundimiento de una nave. En este contexto, un modelo que quizás se podría seguir podría ser el Manual de San Remo de 1994. El artículo 139 de dicho documento precisa, después de reconocer que un barco mercante capturado puede - de forma excepcional- ser destruido, que tal medida sólo se puede efectuar si se cumplen las siguientes reglas: $1^{\circ}$ ) Se debe garantizar la seguridad de los pasajeros y la tripulación. Eventualmente, cuando resulte notorio el buen estado de la mar, las condiciones meteorológicas, la proximidad a tierra o se haga patente la presencia de otra nave que esté en situación de tomarlos a bordo, bastará proveerles con los botes de la nave, pero -en todo caso- debe quedar asegurada la integridad y la vida de la dotación y los pasajeros. $2^{\circ}$ ) Se debe poner a resguardo la documentación y los demás papeles concernientes a la presa. $3^{\circ}$ ) En caso de que sea factible, se deben de tratar salvaguardar los efectos personales de los pasajeros y la tripulación ${ }^{123}$.

${ }^{122}$ Asimismo, el Punto 6.b del Canje de Notas entre la Unión Europea y el Gobierno de Kenia (Cfr. supra nota $n .^{\circ}$ 5), prevé, para caso de entrega de los detenidos a las autoridades de Kenia para su procesamiento, la entrega simultánea de los instrumentos, evidencias del delito y demás bienes incautados.

${ }^{123}$ La necesidad de hacer un exhaustivo registro, será, por tanto, también consecuencia de que -en su caso- se pueda llevar a cabo esta medida. Innecesario es indicar que debe escudriñarse hasta la última dependencia y escondrijo del buque antes de abandonar este y proceder a su destrucción, para evitar que quede a bordo escondida alguna persona secuestrada o algún pirata. Y así se ha procedido, precisamente, en los supuestos citados. En el caso del hundimiento de la ballenera, tras el registro y captura, se procedió a su destrucción, tras lo cual los tres supuestos piratas fueron traslados a la costa de Somalia (véase la noticia «La Armada destruye en el Índico un barco nodriza pirata», en El Mundo, edición de 17 de abril de 2010, p. 18). En el caso del hundimiento del buque del día 25 de abril de 2010, tras la interceptación y la oportuna inspección, «se destruyó el buque nodriza y se dejó marchar a los ocho supuestos piratas, a los que se dejó en uno de sus esquifes cerca de Somalia» (véase la noticia «La Armada destruye otro barco nodriza pirata de los piratas», en El Mundo, 26 de abril de 2010, p. 15). 


\section{PAUTAS EN ORDEN A LA DETENCIÓN DE SOSPECHOSOS}

\section{A) Introducción}

En una clasificación teórico-práctica, Rebato Peño ha diferenciado dos tipos elementales de limitaciones al artículo 17.1 de la Constitución: privación y restricción de libertad ${ }^{124}$. Las primera categoría estaría ligada -en esenciaa la existencia de un proceso penal, presupone la iniciación de ciertas diligencias judiciales y la puesta a disposición del Tribunal competente de las persona presuntamente autora del ilícito penal y/o de los resultados de la investigación. La segunda es más flexible y se identifica con la actividad policial de prevención y mantenimiento de la seguridad general, siendo su principal característica el hecho de ser una medida cautelar breve en el tiempo. Entre estas restricciones se pueden enumerar la retención policial a los solos efectos de identificación, los controles de alcoholemia y estupefacientes y las prácticas policiales de cacheo y registro del sujeto ${ }^{125}$. Esta clasificación -desde el punto de vista de nuestro objeto de estudio- debe de completarse con las previsiones del Derecho Internacional en materia de piratería. En efecto, el Convenio de Ginebra sobre Alta Mar y el Convenio de las Naciones Unidas sobre el Derecho del Mar de 1982 (artículos 22.2 y 110.2, respectivamente) prevén también la retención temporal de la tripulación de un buque, por ejemplo, para el ejercicio del derecho de visita e inspección de la nave. Igualmente el artículo 2.e de la Acción Común 2008/251 PESC ha reconocido que los Estados participantes en la misión "podrán capturar, retener y entregar a las personas que hayan realizado o sean sospechosas de haber cometido actos de piratería».

En el caso de privaciones y restricciones de libertad en el marco de la Operación Atalanta no hay tampoco previstas reglas legales específicas para su realización. En esta situación particular se pueden establecer condiciones excepcionales dadas las propias circunstancias de la vida a bordo de un barco de guerra y la lejanía a puerto; a estos efectos, caben también ciertas limitaciones en los derechos fundamentales reconocidos en el artículo 17.2 y 3 de la Constitución, el derecho a tener asistencia inmediata de un letrado, de puesta a disposición física ante un Juez o de comunicar el hecho de la detención a un familiar, entre otros, revelan esta posibilidad de delimitación en este tipo de detención especial, si bien sin hacer en ella excepción alguna en relación con aquellos derechos fundamentales ligados con la integridad y la dignidad de la persona ${ }^{126}$. En su sentencia de 10 de febrero de 1997, el Tribunal

${ }^{124}$ REBATO PEÑO, M. E., La detención desde la Constitución, Centro de Estudios Políticos y Constitucionales, Madrid, 2006, pp. 27-68.

${ }^{125}$ Ibídem, cit., p. 41.

${ }^{126}$ Compárese, OEHLING DE LOS REYES, A., «Los derechos del detenido...», cit., p. 254. 
Constitucional, ha expresado esta necesidad con las siguientes palabras: la detención «aun realizada fuera de los límites del territorio español, no deja de estar sujeta a la Constitución y al resto del ordenamiento jurídico y, en particular, al respeto de los derechos y libertades que nuestra norma fundamental reconoce y garantiza» (STC 21/1997).

\section{B) Retención a los solos efectos de ejercicio del derecho de visita}

El hecho de que el ejercicio del derecho de visita por parte de un buque de guerra, de conformidad con el artículo 22.2 del Convenio de Ginebra sobre Alta Mar y 110.2 del Convenio de las Naciones Unidas sobre el Derecho del Mar, supone, por un lado, limitación efectiva de la libertad ambulatoria, y, por otro, identificación y además inspección del buque o nave civil, hace ver elementos que van más allá de la mera restricción por un breve periodo de tiempo de la libertad del individuo y se puede hablar no tanto de retención sino de detención ${ }^{127}$. La razón es muy sencilla. Como se sabe, en nuestro ordenamiento interno la figura jurídica de la retención se reserva fundamentalmente para hacer referencia a restricciones de libertad del sujeto breves, exigiéndose, en principio, la realización de la diligencia «de forma inmediata y sin dilación» (STC 341/1993). Los ejemplos más típicos son el «requerimiento de identificación» en vía pública por parte de los funcionarios de policía y el «acompañamiento a dependencias policiales a los solos efectos de identificación», reconocidos en el artículo 20.1 y 2 de la Ley Orgánica 1/1992, de 21 de febrero, de Protección de la Seguridad Ciudadana.

En segundo término, hay que advertir, no obstante, que en nuestro ordenamiento jurídico hay también restricciones de libertad (retenciones), que exceden el sólo hecho de la identificación y, sin embargo, no se consideran tampoco detenciones en sentido estricto. Piénsese, por ejemplo, en el control de alcoholemia y estupefacientes, reconocido por el artículo 12.1 y 2 del Real Decreto 339/1990, de 2 de marzo, de texto articulado de la Ley de Tráfico ${ }^{128}$. Y ello aún cuando la realización de las pruebas puede suponer un periodo

${ }^{127}$ En este sentido, por ejemplo, GARCÍA MORILLO, J., El derecho a la libertad personal: detención privación y restricción de libertad, Tirant lo Blanch, Valencia, 1995, p. 156, para quien la retención solamente es predicable a efectos de identificación.

${ }^{128} \mathrm{El}$ Tribunal Constitucional ha precisado que las previsiones del artículo 17.3 de la Constitución no son aplicables a quien «conduciendo un vehículo de motor, es requerido policialmente para la verificación de una prueba orientativa de alcoholemia, porque ni el así requerido queda, sólo por ello, detenido en el sentido constitucional del concepto, ni la realización misma del análisis entraña exigencia alguna de declaración autoinculpatoria del afectado, y sí sólo la verificación de una pericia técnica de resultado incierto. La verificación de la prueba supone, pues, un sometimiento, no ilegítimo desde la óptica constitucional, al que incluso puede verse obligado sin la previa existencia de indicios de infracción, en el curso de controles preventivos» (STC 107/1985). 
largo de tiempo y el traslado del individuo a un centro sanitario para su consecución ${ }^{129}$. Piénsese, igualmente, en la inspección a la que pueden ser sometidos los viajeros en los aeropuertos, en la que, tras un cacheo inicial, cabe solicitar al sospechoso la realización de una prueba radiológica. Y de hecho, el propio Tribunal Constitucional ha renunciado a delimitar expresamente un plazo para la identificación ${ }^{130}$. Realizando, en esta línea, una interpretación extensiva de estas previsiones, podría deducirse que cabe la posibilidad, teniendo en cuenta las circunstancias y ámbito particular en el que se investiga el ilícito, de considerar el ejercicio del derecho de visita -cuando se procede a la inspección de embarcaciones de pequeña eslora (por ejemplo, un esquife, fueraborda o una embarcación pesquera) sin compartimentos o camarotescomo una retención. No obstante, creemos que el ejercicio del derecho de visita, sin que, al menos, el equipo de inspección informe de las razones del abordaje o sobrepasándose el tiempo «estrictamente necesario» para la realización e indagación de las comprobaciones pertinentes -en los términos del artículo 17.2 del texto constitucional- no sería constitucionalmente admisible ${ }^{131}$.

\section{C) Detención}

En cuanto a la facultad de los miembros del Cuerpo de Infantería de Marina adscritos a la Policía Naval para realizar una detención, ha de decirse que el artículo 490 de la Ley Rituaria atribuye, grosso modo, a «cualquier persona» la capacidad para realizar una detención de todo individuo que vaya a cometer un delito, en caso de descubrir un delincuente in fraganti, de todo aquel que se haya fugado de un establecimiento penitenciario o centro de detención y de aquel procesado que estuviere en rebeldía. La condición de «agente de la autoridad» de los miembros de la Policía Naval, a mayor abundamiento, le fue reconocido por el artículo 580 del Real Decreto 1024/1984, de 23 de mayo, de las Reales Ordenanzas de la Armada, que reconocía que las unidades de la Policía Naval «en ejercicio de sus funciones tendrán el carácter de agentes de la autoridad». Esta calificación del servicio de la Policía

129 Véanse los Capítulos IV y V del Título I del Real Decreto 1428/2003, de 21 de noviembre, por el que se aprueba el Reglamento General de Circulación.

${ }^{130}$ Así, QUERALT JIMÉNEZ, J., Asistencia letrada al detenido, Atelier, Barcelona, 1999, p. 46.

${ }^{131}$ El Tribunal Constitucional ha determinado que las privaciones de libertad distintas a la detención preventiva están igualmente sujetas a las garantías del artículo 17.2 y 3 de la Constitución. El Tribunal Constitucional, reconoce, por ejemplo, para casos de identificaciones en vía pública por parte de las Fuerzas y Cuerpos de Seguridad, la vigencia del derecho a ser informado de las razones de la retención, e incluso, para casos «de una abusiva prolongación» de la diligencia, la vigencia de la previsión del Habeas Corpus (STC 341/1993, de 18 de noviembre, FJ. $6^{\circ}$ ). 
Naval ha sido además ratificada por el punto 3 de la Disposición adicional primera y el artículo 29.2 del Real Decreto 194/2010, de 26 de febrero, por el que se aprueban las Normas sobre seguridad en las FF.AA, reconociendo como ya, por cierto, hacia el artículo 585 de las Reales Ordenanzas de la Armada- su capacidad para intervenir, en ausencia de Cuerpos y Fuerzas de Seguridad y dentro de los márgenes de la Ley de Enjuiciamiento Criminal, en caso de delito flagrante (artículo 32).

En relación con la competencia para realizar una detención por parte de otros miembros de la tripulación, hay que señalar que el punto 4 de la Disposición adicional primera del Real Decreto 194/2010 prevé también que «los miembros de la dotación de los buques de la Armada tendrán el carácter de agentes de la autoridad en el ejercicio de funciones de vigilancia y seguridad marítima atribuidas legalmente o por convenios internacionales suscritos por España»; extendiéndose, por tanto, de igual forma, las funciones de tipo policial, en estos supuestos concretos, no sólo al Comandante -que de por sí asume la máxima autoridad de «mando y policía» del buque (artículo 86 de las Reales Ordenanzas de la Armada)-, sino a toda la oficialidad, a todos los soldados y marinería miembros de la tripulación, indistintamente de su graduación. En este sentido, la posición del Comandante del buque adquiere una posición preferente en la nave y en el radio de acción de la operación, pudiendo ordenar detener en casos de urgencia, en aguas jurisdiccionales o en alta mar, a toda persona que pueda suponer una amenaza para el barco o la tripulación o para otro buque sea militar o civil ${ }^{132}$.

En el supuesto de que se realice una detención, el responsable del operativo (Oficial, Suboficial o Cabo primero) deberá poner inmediatamente a los sujetos sospechosos a disposición de las Fuerzas y Cuerpos de Seguridad del Estado, así como de los posibles efectos o instrumentos del delito, y dará informe - de forma preferentemente escrita dada la importancia del hecho- de entrega y novedades al Jefe u Oficial del que dependa operativamente o al Oficial de guardia. Empero, caso de estar embarcada la Compañía/Sección o en misión en el extranjero, realizando la detención en el marco de una acción de abordaje, en tanto no formen parte de la dotación miembros del Cuerpo Nacional de Policía, de la Guardia Civil o de los GEO, se entiende aplazada la regla de poner a disposición del instituto policial al detenido hasta la llegada del barco a puerto, si bien no se ha de hacer excepción alguna en la obligación de informar al Jefe de la Unidad o al Oficial del que haya dependido la ope-

${ }^{132}$ Algo similar está previsto para el caso del Capitán de un buque civil, dentro del ámbito de su propia nave. Éstos, de conformidad con el artículo 116 de la Ley 27/1992, de 24 de noviembre, de Puertos del Estado y de la Marina Mercante, pueden proceder de forma excepcional a la detención de quien cometa algún tipo de hecho delictivo a bordo. Sobre ello, por ejemplo, CLIMENT DURÁN, C., Detenciones ilegales cometidas por autoridad o funcionario público, Tirant lo blanch, Valencia, 1999, pp. 44-46. 
ración. Una vez el Comandante del buque tiene conocimiento de la detención - tras realizar el pertinente atestado en los términos de los artículo 292 y 496 de la Ley de Enjuiciamiento Criminal- procede comunicarlo a la cadena de mando nacional y multinacional (Comandante del Mando de Operaciones del EMAD y al Comandante de la Fuerza Naval de Atalanta). En principio, sobre todo en el supuesto hipotético de que la detención se haya producido por secuestro de un buque de pabellón español, desde el JEMAD se notifica el hecho de la detención al Juzgado de Guardia de la Audiencia Nacional. En su caso, tras presentación de denuncia del Abogado del Estado e informe del Ministerio Fiscal, el órgano judicial dictará Auto declarándose o no competente para el inicio de las diligencias judiciales. Si el Instructor corrobora la jurisdicción del Tribunal, se presupone, a partir de ese momento, comunicación entre el órgano judicial y el Comandante del buque. Es entonces cuando el Mando interesa al Juez las circunstancias de la detención y, si se conoce, la identidad de los sujetos sospechoso ${ }^{133}$. Finalmente, tras este trámite, el Tribunal dicta nuevo Auto, según criterio, decretando prisión provisional cuando concurran las circunstancias previstas en el artículo 503 de la Ley de Enjuiciamiento Criminal: que conste la existencia de uno o varios hechos que presenten caracteres de ilícito penal y que concurran motivos bastantes para creer responsable criminalmente al individuo contra quien se haya de dictar Auto de prisión $^{134}$.

\section{D) Plazo de detención}

El límite del plazo de detención puede estudiarse desde dos perspectivas: desde la perspectiva del artículo 496 de la Ley de Enjuiciamiento Criminal y desde los artículos 17.2 de la Constitución y 520.1 de la Ley de Enjuiciamiento Criminal. Conforme al primer criterio se entiende que el particular, la autoridad o el agente que haya detenido a una persona debe entregarla al Juez más próximo o ponerla en libertad en plazo de veinticuatro horas. Empero, según el artículo 17.2 de la Constitución y el artículo 520.1 de la Ley Rituaria, se considera que «la detención preventiva no podrá durar más del tiempo estrictamente necesario para la realización de las averiguaciones tendentes al esclarecimiento de los hechos, y, en todo caso, en el plazo máximo de setenta y dos horas, el detenido deberá ser puesto en libertad o a disposición judicial».

${ }^{133}$ Compárese Diario de Sesiones del Congreso de los Diputados, n. ${ }^{\circ} 126$, de 25 de noviembre de 2009, pp. 33 y 34, y n. $^{\circ} 288,11$ de noviembre de 2009, p. 228 y ss.

${ }^{134}$ En los casos que se suscitan en el índico y el Golfo de Adén y costas de Somalia, por delito de piratería (artículos 616 ter y 616 quáter del Código Penal). Cfr. supra Apartado II". 
La distinción jurídica entre el plazo legal y el límite constitucional es, por tanto, en principio, relativa. El primer criterio, presenta una pauta aplicable, dentro del supuesto concreto de restricción de libertad en el mar, por ejemplo, en el caso antes citado de retención para el ejercicio del derecho de visita de una nave. En estos supuestos, si bien la inspección debe realizarse sin sobrepasarse el tiempo «estrictamente necesario» para la realización e indagación de las comprobaciones pertinentes, el traspaso de este límite legal de veinticuatro horas evidenciaría - dependiendo del calado y número de dependencias del barco- una «abusiva prolongación» ${ }^{135}$ de la diligencia y el posible carácter «malicioso» de la detención ${ }^{136}$, pudiéndose catalogar ésta, a partir de ese momento, más como una detención ilegal, en los términos del artículo 530 del Código Penal ${ }^{137}$. En suma: en este tipo de situaciones una vez se han hecho las comprobaciones necesarias y se tiene la mínima constancia de que la tripulación del buque inspeccionado no ha realizado ninguno de los hechos a los que se refiere el artículo 110.1 del Convenio de las Naciones Unidas sobre el Derecho del Mar, debe cesar inmediatamente la detención de la tripulación y, en su caso, del pasaje. El segundo criterio, opera como regla general y presupone que la medida de la detención preventiva en nuestro ordenamiento debe estar determinada por el criterio del «lapso temporal más breve posible» (STC 224/2002), y que, en todo caso, en el plazo máximo de setenta y dos horas -como dice expresamente el artículo 17.2- el sujeto detenido debe ser puesto en libertad o a disposición judicial, como corrobora también el artículo 5.3 del Convenio Europeo de Derechos Humanos, que dispone que el privado de libertad debe ser conducido «sin dilación» a presencia del Juez ${ }^{138}$.

El periodo de detención preventiva es, pues, corto, pero caben, no obstante, excepciones. En este sentido, los artículos 55.1 y 2 y 116 de la Constitución determinan la posibilidad de prórroga de esta medida en las situaciones de alarma, excepción y sitio, en los términos de la Ley Orgánica 4/1981, de 1

${ }^{135}$ Compárese, STC 341/1993, de 18 de noviembre, FJ. $6^{\circ}$.

${ }^{136}$ GIMENO SENDRA, V., Derecho procesal penal, Colex, Madrid, 1999, p. 83.

${ }^{137}$ El artículo 530 de la Ley Orgánica 10/1995, de 23 de noviembre, de Código Penal, se expresa con el siguiente tenor: «La autoridad o funcionario público que, mediando causa por delito, acordare, practicare o prolongare cualquier privación de libertad de un detenido, preso o sentenciado, con violación de los plazos o demás garantías constitucionales o legales, será castigado con la pena de inhabilitación especial para empleo o cargo público por tiempo de cuatro a ocho años».

138 En todo caso, determina la STC 224/2002, FJ. $3^{\circ}$, que la infracción de la norma se produce no sólo por rebasar el plazo de setenta y dos horas, sino también cuando «no habiendo transcurrido ese plazo máximo absoluto, se traspasa el plazo relativo, al no ser la detención ya necesaria por haberse realizado ya las averiguaciones tendentes al esclarecimiento de los hechos, y, sin embargo, no se procede a la liberación del detenido ni se le pone a disposición de la autoridad judicial (STC 224/1998, FJ. $4^{\circ}$ )». 
de junio. En estos casos extraordinarios la autoridad puede proceder a la detención de un individuo por un plazo de hasta diez días (artículo 16.1) ${ }^{139}$. También, en esta línea, el artículo 520 bis.1 de la Ley de Enjuiciamiento Criminal habilita que en casos de delito de terrorismo o participación con banda armada la detención pueda prolongarse hasta durar cinco días. Igualmente, en orden a la situación de detención en alta mar, la superación del plazo de detención resulta justificada, como ha subrayado el Tribunal Europeo de Derechos Humanos en su resolución de 12 de enero de 1999 (caso Rigopoulos v. España), en razón a las circunstancias excepcionales de la detención que justifican un retraso ${ }^{140}$. No sería lógico pretender que, siendo una detención en alta mar tuviera la misma validez práctica el límite temporal de la detención establecido en el artículo 520.1 de la Ley de Enjuiciamiento Criminal, independientemente de las circunstancias y de las millas a que se encuentra el buque de un puerto español. Es cierto que la norma constitucional y legal reconocen la necesidad de que en plazo se ponga al detenido ante la autoridad judicial; pero de ahí no se deriva que ésta deba suponer la puesta a disposición «física» ante el Juez, sino también que «la persona privada de libertad, transcurrido el plazo de las setenta y dos horas, no continúe sujeta a las autoridades que practicaron la detención y quede, aunque sea a distancia, bajo el control y la decisión del órgano judicial competente» ${ }^{141}$. La validez de la prolongación del plazo máximo de detención depende, por tanto, de su supervisión por el Juez y, en su caso, de su decisión «acordando elevar la detención a prisión provisional».

La detención preventiva finaliza con su entrega a la autoridad judicial o con la puesta en libertad del detenido ${ }^{142}$. La puesta a disposición judicial, en el caso específico de la detención en el marco de la Operación Atalanta, reviste dos formas principales: En primer lugar, por medio de la reconversión de la detención en prisión provisional por parte del Juez de la Audiencia Nacional, caso de que el acto de piratería o robo a mano armada en el mar se haya realizado contra un buque de bandera española o así lo decida el órgano judicial, disponiendo asimismo su traslado inmediato a España. En segundo lugar,

${ }^{139}$ Sobre las particularidades de la detención en los supuestos del artículo 116 de la Constitución, véase, por ejemplo, REBATO PEÑO, M. E., La detención desde la Constitución, cit., pp. 103-110.

${ }^{140}$ En sentido parecido, STEDH, Caso Medveyev v. Francia, de 10 de julio de 2008, donde hace referencia a la imposibilidad física en alta mar de conseguir poner a los detenidos rápidamente ante la autoridad judicial.

${ }^{141}$ STC 21/1997, de 10 de febrero de 1997, FJ. $4^{\circ}$ (La referencia a la «distancia» es del Auto del Juzgado Central de Instrucción, de 26 de enero de 1995 [FJ. $1^{\circ}$ ], que conoció de la causa en primera instancia, y que asume, tanto implícita como explícitamente el Tribunal Constitucional en el cuerpo de la sentencia).

${ }^{142}$ REBATO PEÑO, M. E., La detención desde la Constitución, cit., p. 91. 
de conformidad con el denominado «Canje de notas entre la UE y el Gobierno de Kenia», por medio de la entrega a las autoridades policiales de la República de Kenia de los sujetos sospechosos para su inmediata presentación ante un Juez de este país (puntos 2.b y 3.b) ${ }^{143}$. En caso contrario, la puesta en libertad, es aplicable por decisión judicial o cuando de las comprobaciones realizadas por los agentes se deduce su no participación en el hecho delictivo. En fin, también resulta aplicable la puesta en libertad cuando, aún habiendo indicios racionales bastantes que hacen entrever que el detenido ha participado en la comisión de un acto delictivo, en los términos del artículo 492.4 de la Ley Rituaria, lo decide el Mando de la Operación Atalanta y cuando las victimas del acto de piratería no interponen denuncia por el intento de secuestro y robo a mano armada. En estas circunstancias, se procede a la detención temporal de los piratas, comiso de las evidencias e instrumentos del delito y, después, se pone en libertad a los sujetos en la costa de Somalia sin tan siquiera comparecer ante el órgano judicial ${ }^{144}$.

\section{E) Libro-registro de detenidos}

El artículo 20.3 de la Ley Orgánica 1/1992 de Protección de Seguridad Ciudadana atribuye a los funcionarios de las Fuerzas de Seguridad del Estado la obligación de llevar un libro-registro en el que se harán constar las diligencias de identificación realizadas en dependencias policiales, así como los motivos y duración de las mismas, y que estará en todo momento a disposición de la Autoridad Judicial Competente y del Ministerio Fiscal. Igualmente, la Instrucción 12/2009, del Secretario de Estado de Seguridad, por la que se regula el «Libro de Registro y Custodia de Detenidos» determina el deber de

${ }^{143}$ También está previsto su traslado a la República de Seychelles. Véase así el Canje de Notas entre la Unión Europea y la República de Seychelles sobre las condiciones y modalidades de entrega de sospechosos de piratería y robo a mano armada por EUNAVFOR a la República de Seychelles y de su trato después de dicha entrega ( $D O$ L 315, de 2 de diciembre de 2009).

${ }^{144}$ Así se procedió, por ejemplo, cuando el día 23 de marzo de 2010 la fragata Navarra, tras recibir aviso del Mando de la Operación Atalanta, acudió en ayuda de un buque mercante de bandera panameña que estaba siendo atacado por piratas. Tras el abordaje de las embarcaciones, en el registro, se encontró un cuerpo sin vida de uno de los asaltantes que había fallecido tras el tiroteo con el buque panameño, casquillos y armas de distinto calibre. Se procedió después, por tanto, a la detención de seis personas y a la destrucción de la embarcación (véase la noticia «La fragata Navarra detiene a otros seis piratas y recoge a otro, fallecido», en El Mundo, edición de 24 de marzo de 2010, p. 17). Sin embargo, en tanto el armador del buque no formuló denuncia por intento de secuestro para proceder a la entrega de las autoridades judiciales de Kenia, al día siguiente fueron puestos en libertad en la costa de Somalia (véase la noticia «Los seis piratas quedan libres», El Mundo, edición de 25 de marzo de 2010, p. 38). 
los agentes de policía de reseñar en un libro con fichas estandarizadas «las detenciones e incidencias que puedan producirse en dependencias policiales durante el tiempo de permanencia de los detenidos en las mismas» ${ }^{145}$. Esta regla sencilla y práctica también ha sido reconocida por el Tribunal Europeo de Derechos Humanos, que ha entendido que «para que la detención de una persona sea compatible con las exigencias del artículo 5.1 del Convenio Europeo de Derechos Humanos, es necesario que se registren con la máxima precisión los datos del detenido, la hora, el lugar, los motivos de la detención y el nombre de las personas responsables de la misma» ${ }^{146}$. Realizando una interpretación extensiva del tenor literal de estos preceptos puede deducirse que cabe la necesidad para casos de detenciones realizadas por la Policía Naval en este tipo de operaciones -que aunque no son realizadas en las típicas dependencias policiales como la Comisaría, el Cuartelillo, Puertos o Aeropuertos o Puestos fronterizos requieren de un plus adicional de control por realizarse en el mar y a miles de kilómetros de España- de llevar, por parte del Mando competente, un libro-registro de personas retenidas y detenidas.

\section{F) Derechos del detenido}

El artículo 520.1 de la Ley de Enjuiciamiento Criminal, que perfila los derechos fundamentales reconocidos en el artículo 17.3 de la Constitución, dispone que la detención debe realizarse -en lo posible- en la forma que menos perjudique al detenido o preso. Teniendo en cuenta esta premisa, en términos generales, se reconocen las siguientes garantías a la persona detenida: derecho a ser informado de las razones de la detención y de los derechos que le asisten, derecho a guardar silencio y no ser obligado a declarar, derecho a la asistencia de un letrado, derecho a comunicar a un familiar o persona que se desee el hecho de la detención, derecho a interprete, derecho a interponer recurso de habeas corpus y derecho a reconocimiento médico. Empero, el alcance de estos derechos puede ser -de conformidad con la doctrina del Tribunal Constitucional y el Tribunal Supremo- delimitado para casos de arresto en el mar, como consecuencia de la especialidad y circunstancias que supone la detención en un punto muy alejado de puerto y la privación de libertad en un buque. En este contexto, cabe distinguir derechos susceptibles de 7532 .

${ }^{145}$ Véase en Boletín Oficial de la Guardia Civil n. ${ }^{\circ}$ 35, de 18 de diciembre de 2009, p.

${ }^{146}$ Así, ÁLVAREZ GARCÍA F. y QUERALT JIMÉNEZ, A., «El derecho a la libertad y a la seguridad y su sistema de garantías en el Convenio de Roma: Un estándar mínimo europeo», en GARCÍA ROCA, J. y SANTOLAYA MACHETTI, P., (Coords.), La Europa de los derechos..., cit., p. 159. La nota a pie nos remite a los siguientes SSTEDH: Caso Çakisi v. Turquia, de 8 de julio de 1999, Caso Anguelova v. Bulgaria, de 13 de junio de 2002 y Caso Orhan v. Turquia, de 18 de junio de 2002 . 
delimitación (no de privación) y derechos fundamentales ligados con la dignidad y la integridad de la persona que no se pueden restringir en ningún caso; a estos efectos, el derecho a ser informado inmediatamente de sus derechos y de las razones de la detención, el derecho a la asistencia de un abogado, derecho a comunicar el hecho de la detención y el derecho a interponer recurso de habeas corpus, se califican como garantías delimitables, sin poder hacer limitación alguna en el derecho a no ser forzado a declarar y en el derecho a reconocimiento médico ${ }^{147}$.

\section{a) Garantía de información al detenido}

La garantía de información al detenido, en el plano teórico-jurídico, como se ha dicho, se concreta en la obligación de informar al detenido con carácter inmediato -en el plazo más breve posible y en una lengua que comprenda, en términos del artículo 5.2 del Convenio Europeo de Derechos Humanos- de las razones que han motivado su privación de libertad y de los derechos que le asisten ${ }^{148}$. La aplicación práctica, sin embargo, de este requisito, en el contexto de una detención en el marco de una operación en alta mar o en el mar territorial de otros Estados depende, como es lógico, de la posibilidad de que a bordo del buque de la Armada se encuentre alguien que hable y comprenda la lengua de las personas detenidas o retenidas, cosa no siempre factible. Lo que supone que la posibilidad de implementación de esta exigencia en sus estrictos términos tenga que efectuarse dependiendo de las circunstancias y de los medios humanos y técnicos de que se disponga a bordo. En caso de que se proceda a la detención, si bien el Tribunal Europeo de Derechos Humanos, (Caso Fox, Campbell y Hartley v. Reino Unido, de 30 de agosto de 1990) reconoce que «la persona privada de libertad no necesita ser expresamente informada (...), si esta información puede deducirse de las circunstancias del caso» ${ }^{149}$, en la práctica, en caso de que ninguno de los miembros del comando de abordaje conozca el idioma de la tripulación contraria o estos no sepan inglés, cabe proceder a la información tan pronto la lancha con los arrestados llegue al buque de guerra y suban a bordo ${ }^{150}$. En último extremo, el barco puede disponer de impresos de información sobre el delito de piratería y de derechos en las lenguas más comunes del teatro de

${ }^{147}$ OEHLING DE LOS REYES, A., «Los derechos del detenido...», cit., pp. 254 y 257.

${ }_{148}$ FERNÁNDEZ SEGADO, F., El sistema constitucional español, Dykinson, Madrid, 1992, p. 244.

149 ÁLVAREZ GARCÍA, F. y QUERALT JIMÉNEZ, A., «El derecho a la libertad y a la seguridad...», cit., p. 176.

${ }^{150}$ De esta manera se procede, por ejemplo, salvando las distancias, cuando el agente de policía ha realizado la detención de un extranjero en la vía pública, proporcionándole un interprete no en el mismo momento de la detención, sino cuando se produce la llegada a comisaría. 
operaciones o, proceder a la comunicación directa de un intérprete por vía telefónica o videoconferencia ${ }^{151}$.

\section{b) Derecho a no ser obligado a declarar}

En sentido estricto, la detención de un civil en circunstancias normales por parte de miembros de un patrulla de la Policía Militar sólo procede en casos excepcionales, particularmente, en ausencia de funcionarios de policía, y se extiende hasta que $-\ll \tan$ pronto como sea posible»- proceden a poner a disposición de los miembros de las Fuerzas y Cuerpos de Seguridad del Estado al delincuente y las evidencias del delito, no pudiendo, en principio, proceder al interrogatorio de aquellos (artículo 32 del Real Decreto 194/2010). Empero, ya hemos dicho que en caso de misiones en el extranjero, en alta mar o en el mar territorial de otro Estado, en tanto no formen parte de la dotación miembros del Cuerpo Nacional de Policía, de la Guardia Civil o de los GEO, se entiende aplazada la regla de poner a disposición del instituto policial al detenido hasta la llegada del barco a puerto.

El interrogatorio realizado a los sospechosos, realizado en el marco de la Operación Atalanta, es una medida excepcional y sumaria destinada más a obtener información sobre posibles datos de posición y previsibles actuaciones de los piratas ${ }^{152}$. En caso de toma de declaración por parte de los miembros de la Policía Naval, al igual que el interrogatorio en dependencias policiales realizado por miembros de las Fuerzas y Cuerpos de Seguridad, después de «invitar a declarar al detenido» ${ }^{153}$, haciéndolo motu proprio, no pretende resolver la cuestión de fondo, sino, solamente, registrar algún elemento identificativo relativo al ilícito de valor meramente indiciario (artículo 406 de la Ley Rituaria), y, en su caso, útil para su apunte en el Libro-Registro de detenidos y la formalización del atestado. En este contexto, también cabría aquí, particularmente cuando la detención preventiva pasa a detención provisional por decisión del órgano judicial, la posibilidad de proceder -en los términos establecidos por el artículo 229 de la Ley Orgánica del Poder Judi-

${ }^{151}$ En estas circunstancias, hay que diferenciar derechos que se pueden implementar por medio de otros sistemas que no sean la comunicación hablada y otros que requieren obligatoriamente la intervención de un intérprete. «Es evidente que el derecho a ser asistido de un intérprete deriva del desconocimiento del idioma castellano que impide al detenido ser informado de sus derechos, hacerlos valer y formular las manifestaciones que considere pertinentes ante la administración policial, pues si alguno de esos derechos pudieran respetarse por otros medios (la simple información, por ejemplo, por un texto escrito en la lengua que entienda el detenido) otros derechos, que suponen un diálogo con los funcionarios policiales, no pueden satisfacerse probablemente sin la asistencia del intérprete» (STC 74/1987, FJ. $3^{\circ}$, de 25 de mayo).

${ }^{152}$ Véase POOLE QUINTANA, F., «Contra los piratas en el Golfo de Adén», cit., 828.

${ }^{153}$ QUERALT JIMÉNEZ, J., Asistencia letrada al detenido, cit., p. 72. 
cial- a su interrogatorio por el Juez vía videoconferencia o webcam ${ }^{154}$.

El derecho a no declarar engloba el derecho a permanecer en silencio y a no contestar alguna o algunas preguntas que se formulen ${ }^{155}$. La Policía Naval -en caso de que el detenido, por casualidad, hable alguna de las lenguas europeas más conocidas (inglés, francés, etc.) o medie la presencia de un interprete- puede, como hemos dicho, invitar a declarar pero no forzar. la práctica de la diligencia, de acuerdo con los artículo 388 y siguientes de la Ley de Enjuiciamiento Criminal, se inicia preguntando al detenido su nombre y datos personales, así como por su participación en los hechos y grado de participación de otros sujetos. «Si con estas o por cualquier otra circunstancia se observa que el detenido ha "perdido la serenidad" deberá concedérsele un tiempo para descansar y recuperar la calma; siendo totalmente ilegítimos los interrogatorios privando al detenido de sueño o realizados cuando este se encuentre en mala condición física o psíquica» ${ }^{156}$, por ser también contrarios al principio de dignidad y al derecho a la integridad física y moral de la persona (artículos 10.1 y 15 de la Constitución). Obvio es decir, por ello, que caso de que el detenido manifieste o haga notar que se encuentra enfermo o en mal estado debe llamarse al sanitario de a bordo para que proceda a realizarle un examen. En este sentido, hay que señalar además que nuestro Derecho interno prohíbe terminantemente cualquier exceso físico o psíquico para obtener una declaración del detenido, pudiéndose incurrir en estos casos en infracción penal (artículo 76 del Código Penal Militar).

\section{c) Derecho a asistencia de un abogado}

La garantía de intervención de un abogado, al margen del tema objeto de estudio, desde una perspectiva general, ha sido objeto de notables equívocos. $\mathrm{Al}$ otorgar muchas veces plena validez a la declaración obtenida con la anuencia del detenido en dependencias policiales con carácter previo a la personación del letrado en el centro de detención -de conformidad con el artículo 520.4 in fine-, se ha relativizado la importancia de este derecho fundamental, que se tacha de mera fórmula de procedimiento subsanable, en su caso, a posteriori en el juicio oral ${ }^{157}$. Pero si se contrapone a esta interpretación rala del artículo 17.3 de la Constitución la idea de que el abogado asume en la prestación de la asistencia al privado de libertad la relevante función de «garante

${ }^{154}$ Sobre la utilización de este sistema técnico, brevemente, DE HOYOS SÁNCHEZ, M., «Euro-orden y causas de denegación de entrega», en SANZ MORAN, A., Cooperación judicial penal en la Unión Europea: La orden europea de detención y entrega, Lex Nova, Valladolid, 2005, pp. 303 y 304.

${ }^{155}$ Así VIDAL ANDREU, G., «Detención y prisión preventiva», en ANDRÉS IBÁÑEZ, P., Detención y prisión provisional, Consejo General del Poder Judicial, Madrid, 1996, p. 394.

${ }^{156}$ REBATO PEÑO, M. E., La detención desde la Constitución, cit., p. 193.

${ }^{157}$ Sobre ello, QUERALT JIMÉNEZ, J., Asistencia letrada al detenido, cit., p. 74. 
de la integridad física del detenido, y de evitar la autoinculpación por ignorancia de los derechos que le asisten» (STS de 19 de septiembre de 1994) ${ }^{158}$, la necesidad de implementación de esta regla en sus estrictos términos cobra mayor coherencia. «La intervención del letrado -dice también expresivamente el Tribunal Constitucional- responde a la finalidad, de acuerdo a lo dispuesto en el artículo 520.2 de la Ley de Enjuiciamiento Criminal, de asegurar, con su presencia personal, que los derechos constitucionales del detenido sean respetados, que no sufra coacción o trato incompatible con su dignidad y libertad de declaración y que tendrá el debido asesoramiento técnico sobre la conducta a observar en los interrogatorios, incluida la de guardar silencio, así como su derecho a comprobar la fidelidad de lo trascrito en el acta de declaración que se le presente a la firma» ${ }^{159}$.

El Tribunal Constitucional, en la STC 21/1997, no obstante, ha matizado a este respecto que la virtualidad de este derecho -como también del derecho a ser informado de las razones de la detención y de los derechos que le asisten- tiene su sentido pleno en orden a la realización de las averiguaciones tendentes al esclarecimiento de los hechos. Y éstas, en circunstancias normales, se realizan en dependencias policiales, no en el hecho fáctico del traslado. En el caso de detención en el mar, la misión de los miembros del buque de la Armada no es hacer esta función, sino proceder a la captura del barco, inspeccionarlo y detener a los presuntos responsables de actos de piratería. Si se me permite la comparación, en este caso concreto, su función es -salvando las distancias- homologable a la que realiza el coche celular que traslada a unos sospechosos a comisaría. Es ahí donde, a juicio del Tribunal Constitucional, tiene lugar la investigación de los hechos y donde cobran verdadero sentido estas garantías constitucionales para evitar la indefensión del acusado ${ }^{160}$.

En conclusión: no hay jurídicamente duda de que la garantía de asistencia letrada es aplicable a la detención por la Policía Naval en el mar ${ }^{161}$; sin embargo, en tanto la diligencia de toma de declaración no se realice a bordo ni en el traslado del detenido, limitándose a interrogar al arrestado sobre cuestiones de mera identificación y solicitar información de interés para la operación, de no admitirse otras soluciones ${ }^{162}$ quedaría excepcionalmente fuera de

${ }^{158}$ Véase así BEJERANO GUERRA, F., «La asistencia letrada al detenido», en Sepínnetrevista de práctica penal, mayo-junio n. ${ }^{\circ}$ 15, Madrid, 2005, p. 42.

${ }_{159}$ Entre otras SSTC 196/1987, de 11 de diciembre, 252/1994, de 19 de septiembre, 229/1999, de 13 de diciembre, 199/2003, de 10 de noviembre.

${ }^{160}$ OEHLING DE LOS REYES, A., «Los derechos del detenido...», cit., p. 255.

${ }^{161}$ Compárese, REBATO PEÑO, M. E., La detención desde la Constitución, cit., p. 217.

${ }^{162}$ En este sentido, REBATO PEÑO, M. E., La detención desde la Constitución, cit., p. 217, quien reconoce que la mejor solución, aún en casos de detención en alta mar, sería proveer al detenido de la asistencia de un abogado «desde el primer instante en que esto sea posible». En lo que se refiere a casos de detención en buque de guerra, desde nuestro punto de vista, para cubrir esta regla constitucional fundamental en este tipo de operaciones, podría procederse a la activación y embarque de un Oficial RV, abogado en ejercicio en la vida civil, (compárese, Supra nota n. ${ }^{\circ} 109$ ). 
la necesidad de asistencia inmediata de un abogado, siempre y cuando la participación del arrestado se realice voluntariamente y sin mediar ningún tipo de presión.

\section{d) Derecho a comunicar el hecho de la detención}

La regla de permitir al detenido comunicar el hecho de la privación de libertad a un familiar o allegado -y en caso de ser extranjero de ponerse en contacto con la Oficina Consular de su país- admite excepciones según la Ley. El artículo 520 bis de la Ley de Enjuiciamiento Criminal limita este derecho en casos de detenidos sospechosos de terrorismo y colaboración con banda armada. El artículo 509.1 de la misma también prevé la aplicabilidad de esta medida especial «para evitar que se sustraigan a la acción de la justicia personas supuestamente implicadas en los hechos investigados, que éstas puedan actuar contra bienes jurídicos de la víctima, que se oculten, alteren o destruyan pruebas relacionadas con su comisión, o que se cometan nuevos hechos delictivos». La función de esta previsión va dirigida a «aislar al sospechoso con objeto de lograr el mayor esclarecimiento de los hechos que se le imputan» (STS de 12 de junio de 1998), pero también, de forma general, para asegurar la protección de valores garantizados por la Constitución y a efectos de proporcionar seguridad a los ciudadanos ${ }^{163}$. Es esta doble exigencia, pretender el rápido esclarecimiento de los hechos y evitar la fuga de otros presuntos participantes en la comisión del ilícito o la eliminación de evidencias del delito, la que obliga inexcusablemente -presumiendo una posible «confabulación» con familiares y amigos (como suele ocurrir en caso de terrorismo)- a adoptar una medida de este tipo ${ }^{164}$.

La base para la restricción de esta garantía en el caso de personas privadas de libertad a bordo de un buque de la Armada, en el marco de una operación en el extranjero, radica, por lo mismo, en que el propio hecho de la detención y, en su caso, el traslado de los detenidos podría verse afectado si se permitiera a éstos comunicar el hecho del abordaje de su embarcación y su detención a cualquier persona, pudiendo así, además, poner en peligro el éxito de la operación, al poner sobre aviso, por ejemplo, a otros piratas que operan en la zona, que podrían escapar de la acción de la justicia o, incluso, organizar una operación de ataque o rescate.

${ }^{163}$ FERNÁNDEZ SEGADO, F., «Suspensión de los derechos y libertades. Comentario introductorio al Capítulo V», en ALZAGA VILLAMIL, O., Comentarios a las Leyes políticas, Vol. IV, EDERSA, Madrid, 1986, p. 624; el mismo autor en El sistema constitucional español, Dykinson, Madrid,1992 p. 248. .

${ }^{164}$ Compárese, ORBEGOZO ORONOZ, I. / PÉREZ MACHÍO, A. / PEGO OTERO, L., La suspensión individual de derechos en supuestos de terrorismo: Especial consideración a la detención incomunicada, Publicaciones del Ararteko Vasco, Vitoria, 2009, p. 69. 


\section{e) Derecho a interponer recurso de habeas corpus}

En todos los puntos precedentes con relación a la detención hemos visto cómo las distintas previsiones de esta medida cautelar se ordenan alrededor de dos principios básicos: la garantía de la libertad personal y la realización de ésta bajo unos mínimos de seguridad e integridad del sujeto durante el periodo de restricción de libertad ${ }^{165}$. El procedimiento de habeas corpus, expresamente aludido en el artículo 17.4 de la Constitución, se constituye en mecanismo adicional de control judicial de estos fines de rango fundamental y de cada una de las garantías preventivas: duración de la detención, derechos del detenido y prisión preventiva ${ }^{166}$. Este proceso -regulado en la Ley Orgánica 6/1984, de 24 de mayo, reguladora del procedimiento de Habeas Corpus - es un sistema rápido y eficaz para evitar y hacer cesar de manera inmediata las posibles vulneraciones de los derechos del detenido mediante la puesta a disposición ante el órgano judicial de la persona privada de libertad (STC 208/2000). La acción de habeas corpus no pretende resolver el problema litigioso de fondo, sino, solamente, una comprobación profunda sobre la legalidad o ilegalidad de la detención. De este modo, una vez examinados por el Juez los requisitos de la solicitud, de haber escuchado a las partes (también al detenido) y practicado las demás actuaciones que prevé la ley, el órgano judicial, si estima que se ha producido alguna irregularidad, mandará la puesta a disposición judicial o en libertad del sujeto, su traslado a otro centro de detención o la subsanación de los fallos que se hallan podido observar en la detención (artículo 8 de la Ley Orgánica 6/1984).

Empero, en el caso de detención en alta mar, también en razón a la especialidad de las circunstancias y particularidad del marco donde tiene lugar el arresto y el traslado del detenido, la superación del plazo legal de privación de libertad no habilita inmediatamente a la interposición de recurso de $h a$ beas corpus. En estos casos excepcionales, como se ha dicho anteriormente, no sería lógico pretender que, siendo una detención practicada a muchas millas de distancia de un puerto nacional, tuviera la misma validez el límite temporal de setenta y dos horas establecido en el artículo 17.2 de la Constitución. En tales circunstancias, si bien se podrían realizar de forma extraordinaria alguna de las diligencias procedimentales del proceso por vía de videoconferencia, transcurrido el plazo de detención, basta únicamente con asegurar que el privado de libertad no continúa sujeto a las autoridades que practicaron la detención y quede, aunque sea a distancia, bajo control y supervisión del ór-

${ }^{165}$ Véase QUERALT JIMÉNEZ, A., La interpretación de los derechos: del Tribunal de Estrasburgo al Tribunal Constitucional, Centro de Estudios Políticos y Constitucionales, Madrid, 2008, p. 274.

${ }^{166}$ Véase GARCÍA MORILLO, J., «Algunas consideraciones sobre el reconocimiento constitucional de la libertad personal», en el colectivo Homenaje a Joaquín Tomás Villarroya, Fundación Valenciana de Estudios Avanzados, Valencia, 2000, pp. 572 y 574. 
gano judicial competente. Esta doctrina ha sido sentada por la STC 21/1997 -se remonta al caso del ciudadano griego Angelos Rigopoulos, capitán del buque de bandera panameña Archangelos, capturado por un buque del Servicio de Vigilancia Aduanera en aguas internacionales en el Atlántico y que permaneció detenido a bordo durante diecisiete días hasta que arribó a Las Palmas- y ha sido avalada por el Tribunal de Estrasburgo en el caso Rigopoulos v. España de 12 de enero de 1999 y en el caso Medveyev v. Francia, de 10 de julio de $2008^{167}$.

${ }^{167}$ Hay que hacer notar, sin embargo, que esta solución no es del todo indicada en otro tipo de fallos de las previsiones legales de la detención, por ejemplo, para el caso hipotético de trato vejatorio o presiones por parte de alguno de los miembros de seguridad del buque. Una vez más se hace patente la necesidad de disponer en este tipo de operaciones de la presencia de un letrado en ejercicio. La Ley Orgánica 6/1984 faculta al Juez en este estado de cosas a mandar que se ponga al detenido «en establecimiento distinto, o bajo la custodia de personas distintas de las que hasta entonces la detentaban». En último extremo, el traslado a otro buque de la Armada participante en la misión o su traslado inmediato, en su caso, vía aérea, a España o a una base de alguna de las misiones en las que participan las FF.AA en el extranjero, podría ser una solución. 